\title{
Vibration Frequencies Extraction of the Forth Road Bridge Using High Sampling GPS Data
}

\author{
Jian Wang, ${ }^{1,2}$ Xiaolin Meng, ${ }^{2,3}$ Changbiao Qin, ${ }^{1}$ and Jiaohong Yi ${ }^{1}$ \\ ${ }^{1}$ School of Environment Science and Spatial Informatics, China University of Mining and Technology, Xuzhou 221116, China \\ ${ }^{2}$ Sino-UK Geospatial Engineering Centre, The University of Nottingham, Nottingham NG7 2TU, UK \\ ${ }^{3}$ Nottingham Geospatial Institute, The University of Nottingham, Nottingham NG7 2TU, UK \\ Correspondence should be addressed to Jian Wang; wjianhuance@163.com
}

Received 3 July 2015; Accepted 8 September 2015

Academic Editor: Salvatore Russo

Copyright (C) 2016 Jian Wang et al. This is an open access article distributed under the Creative Commons Attribution License, which permits unrestricted use, distribution, and reproduction in any medium, provided the original work is properly cited.

\begin{abstract}
This paper proposes a scheme for vibration frequencies extraction of the Forth Road Bridge in Scotland from high sampling GPS data. The interaction between the dynamic response and the ambient loadings is carefully analysed. A bilinear Chebyshev highpass filter is designed to isolate the quasistatic movements, the FFT algorithm and peak-picking approach are applied to extract the vibration frequencies, and a GPS data accumulation counter is suggested for real-time monitoring applications. To understand the change in the structural characteristics under different loadings, the deformation results from three different loading conditions are presented, that is, the ambient circulation loading, the strong wind under abrupt wind speed change, and the specific trial with two $40 \mathrm{t}$ lorries passing the bridge. The results show that GPS not only can capture absolute 3D deflections reliably, but also can be used to extract the frequency response accurately. It is evident that the frequencies detected using the filtered deflection time series in different direction show quite different characteristics, and more stable results can be obtained from the height displacement time series. The frequency responses of 0.105 and $0.269 \mathrm{~Hz}$ extracted from the lateral displacement time series correlate well with the data using height displacement time series.
\end{abstract}

\section{Introduction}

The Global Navigation Satellite Systems (GNSS) positioning technology has been widely used in monitoring dynamic responses of civil structures, such as high-rise building and cable-stayed bridges, for more than twenty years. In order to obtain the deflection and the vibration frequencies of bridges, many efforts have been made by the academic to develop monitoring systems and data processing algorithms.

By using the Global Positioning System (GPS), Leach et al. proposed a monitoring system of a cable-stayed suspension bridge to obtain the deformation and the vibration [1]. In 1995, the capability of GPS for monitoring the structural vibrations was verified with an experiment that was performed in the Calgary Tower; a vibration frequency of $0.3 \mathrm{~Hz}$ in both north-south and east-west directions was extracted [2]. Two experiments were performed for the extraction of the short-term deformations of the suspension bridge at Tulln in Austria and the results show that the precision of a GPS monitoring system is about $2 \mathrm{~mm}$ for the horizontal coordinates and $4 \mathrm{~mm}$ for the height component [3]. To monitor the high frequency characteristic of a bridge, a Leica SR510 receiver of $10 \mathrm{~Hz}$ sampling rate and a JNS100 receiver measured at $50 \mathrm{~Hz}$ were used and the trials were carried out in a controlled environment; the real bridge monitoring has proved the effectiveness of high sampling GPS [4]. To improve the reliability of a system for bridge deflection monitoring, an integrated GPS/Pseudolites system was proposed and its geometric characteristic was analysed [5]. The vertical natural frequency of the Pierre-Laporte Bridge in Canada was extracted using different algorithms and programs based on GPS monitoring data [6]. A motion simulation table was designed to simulate $2 \mathrm{D}$ motion of high-rise building in a horizontal plane and motion of long span bridges in a vertical plane; then a GPS antenna was installed on the table for collecting the data of a simulated motion. It demonstrated that GPS data is accurate enough for monitoring the dynamic response of civil structures [7]. 


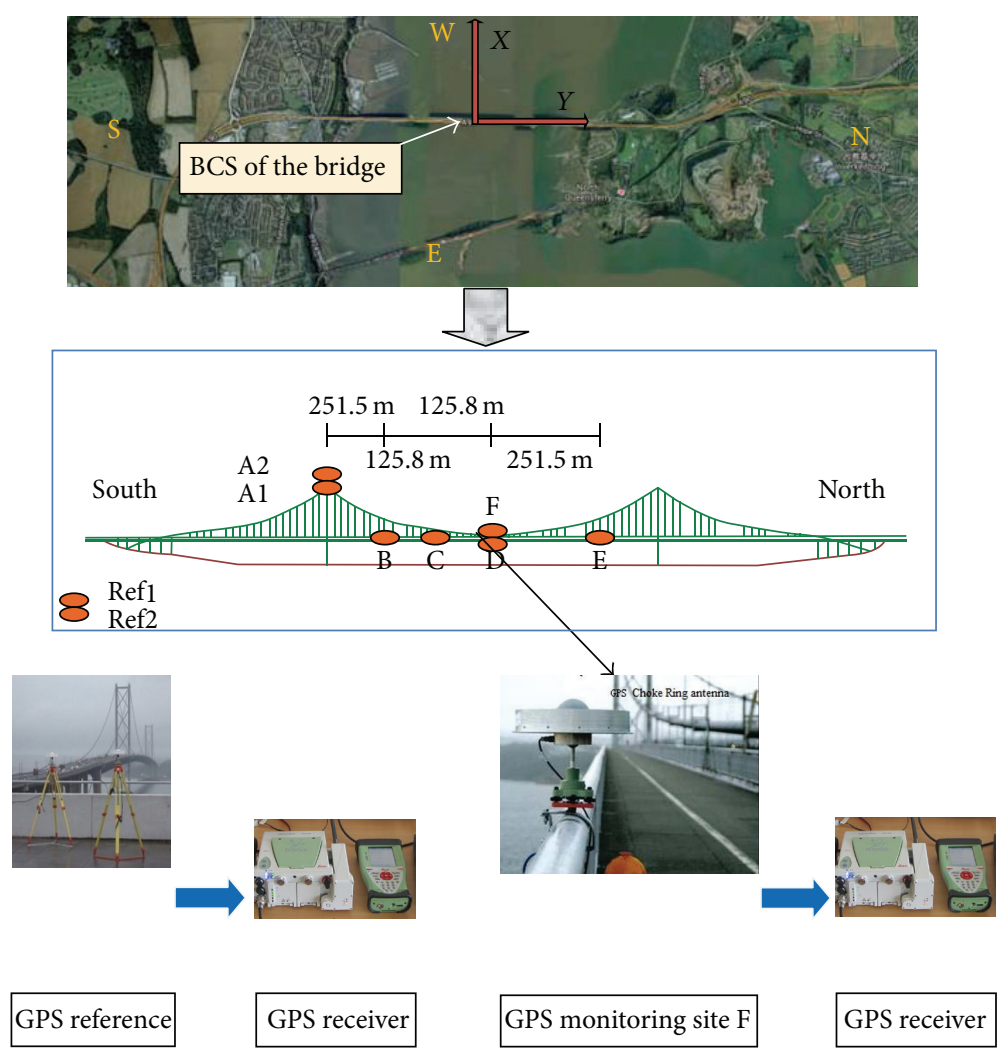

FIGURE 1: The devices used to monitor the dynamic responses of the Forth Road Bridge (only the data from site F will be analysed).
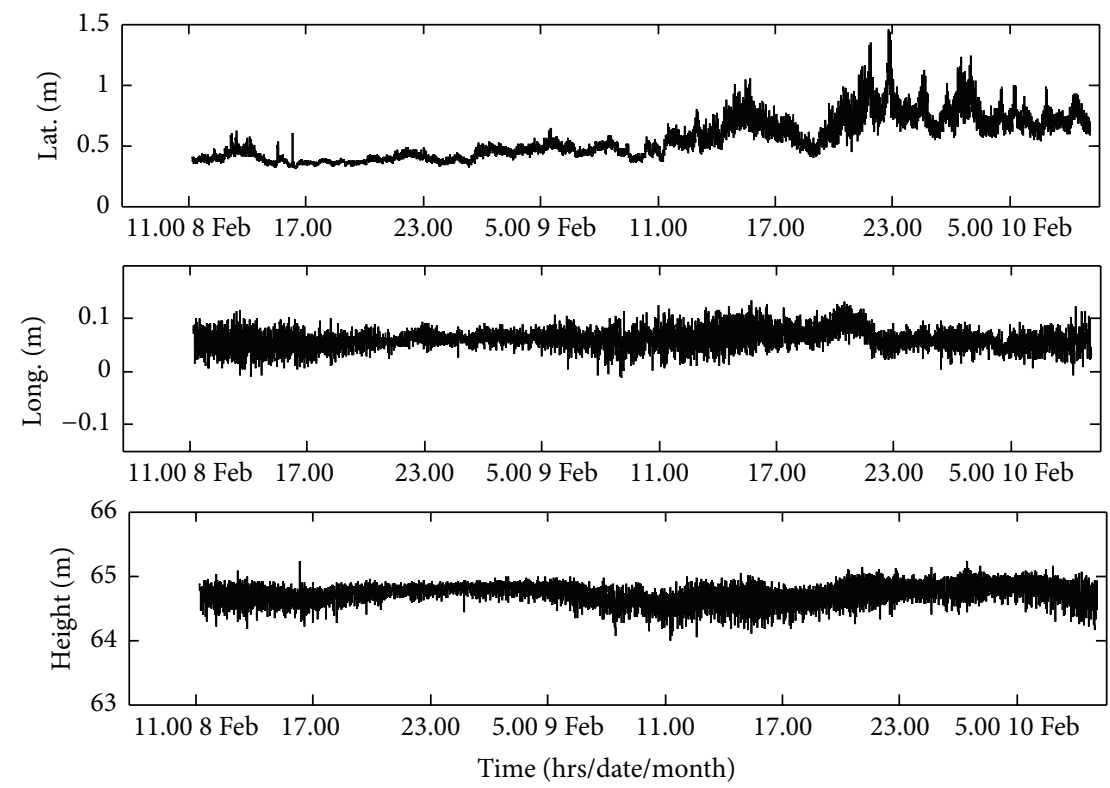

FIGURE 2: Lateral, longitudinal, and vertical deflection in BCS during the $46 \mathrm{~h}$ trial.

A statistical analysis on the outlier level and the accuracy of the real-time kinematic (RTK) and postprocessing kinematic modes were given by Nickitopoulou through using the data collected via a rotating GPS receiver antenna [8]. It can be concluded that GPS is viable to record the responses of forced vibration, decayed free vibration, and ambient vibration of the Wilford Bridge over the River Trent in Nottingham and a triaxial accelerometer can be used to validate the dynamics estimated from GPS measurements [9]. The structural deflection of a cable-stayed bridge over the River Tamar in northern Tasmania, Australia, has been successfully detected using GPS monitoring data and the predicted deflection 


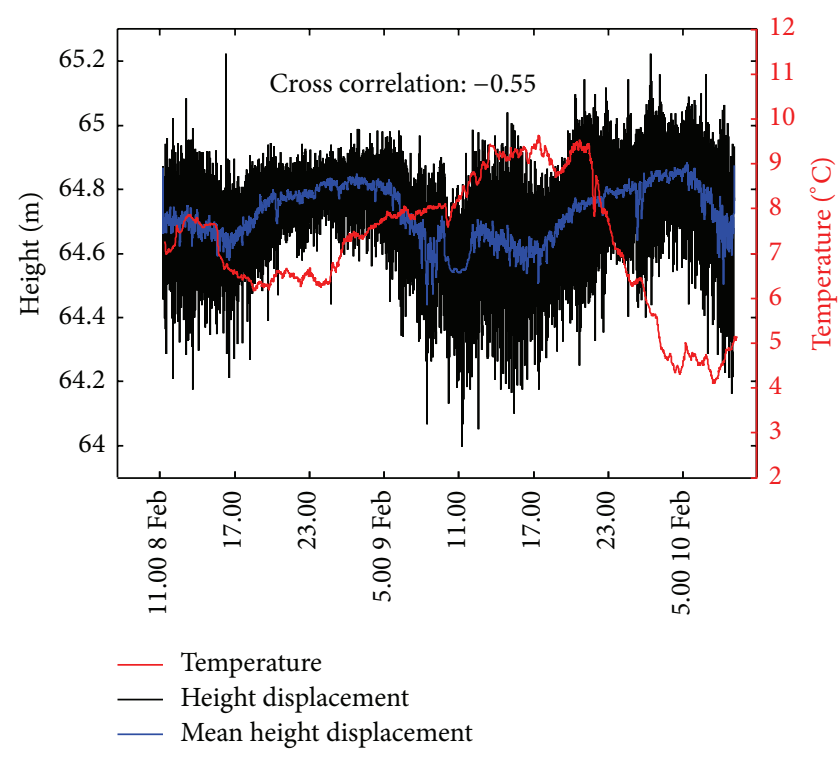

FIGURE 3: Relation between the air temperature and height deflection at site $\mathrm{F}$

calculated using the SPACE GASS structural analysis software suite was used to verify the GPS results [10]. The spectral density of deflections monitored via a RTK GPS installed on the Dalian Beida Bridge is in coincidence with that of a finite element model (FEM) [11]. The study also reveals the potential of GPS to measure the deflections and the modal frequencies of rather stiff bridges, far exceeding current limits of the method assumed so far, which was verified via an example by monitoring the oscillations of a $40 \mathrm{~m}$ long steel footbridge [12]. GPS was also suitable for the identification of relatively rigid bridges with modal frequencies up to $4 \mathrm{~Hz}$ [13]. The mean amplitude of oscillations was calculated with millimetre accuracy via a computer based algorithm using GPS and Robotic Theodolites (RTS) and the method was used to two short span bridges for the structural health monitoring [14]. Im et al. reviewed GPS technology for structural health monitoring [15]. GPS is a viable and promising tool for vibration extraction considering the rapid advancement of GPS devices and algorithms. Modal frequencies of the Wilford Bridge are accurately identified using GPS measurements with a proposed Multimode Adaptive Filtering (MAF) algorithm and validated by accelerometer data. The fundamental frequency $1.690 \mathrm{~Hz}$ of the bridge was detected which is slightly lower than the estimated frequency $1.740 \mathrm{~Hz}$ by the structural analysis [16].

Wind loading and multipath effects mainly contribute to low frequency components of bridge dynamics which are difficult to separate and affect early alarming. The amplitude of multipath effect can reach a few centimetres in extreme environment and an adaptive filtering method can mitigate the multipath effect for structural deflection monitoring [17, 18]. Dynamic multipath induced by a passing vehicle for bridges was studied for the first time and certain strategies for modelling were proposed [19]. Actually, monitoring stations have varying circumstance that produces different multipath effects that will be considered in this paper.
This paper proposes an innovative scheme for extracting the vibration frequencies from high sampling GPS data of the Forth Road Bridge. In order to extract the deflection, a Chebyshev high-pass digital filter is designed to eliminate multipath effects and then an FFT is used to extract the frequencies information. The field experiment for the Forth Road Bridge is introduced in detail and the data set of a middle site on the west side of the bridge deck is chosen for analysing the frequency responses. The frequency response in different situations is analysed and compared to obtain the natural frequencies of the bridge.

\section{Field Experiment}

2.1. The Forth Road Bridge in Scotland. The Forth Road Bridge, opened to traffic in 1964, links the north of Scotland with Edinburgh and the south, carrying the A90 road of United Kingdom (UK). It has an overall length of $2.5 \mathrm{~km}$ and a main span length of $1006 \mathrm{~m}$. The road bridge runs at $3^{\circ}$ from north. The traffic has increased from 4 million vehicles in 1964 to over 23 million in 2002. In order to investigate the dynamic responses of the Forth Road Bridge, an overall experiment was carried out in 2005 by a research group of the University of Nottingham and the work on the data processing of the deflection and frequency monitoring of the Forth Road Bridge has been reported in 2012 [20].

2.2. Description of the Experiment. During a 46 h observation period from 8 to 10 February 2005, the data sets were collected by the staff from the former Institute of Engineering Surveying and Space Geodesy (IESSG) at the University of Nottingham; a part of the field data sets is used in this paper to extract the vibration frequencies in various ambient loadings. Five GPS receivers marked as B, C, D, E, and F were fixed to the bridge handrail and two GPS receivers marked as A1 and A2 were located on top of the southern support tower as illustrated in Figure 1 [20].

More details of the receivers' locations and their specifications are found in [20] and an overall analysis and comparisons of the observations of the GPS receivers were demonstrated in [20]. Data collected at station F is applied to test the proposed scheme as the weather station was installed exactly adjacent to $\mathrm{F}$ at the midspan on the western footway. A Leica GX1230 dual-frequency GPS receiver equipped with a Leica AT504 choke-ring antenna was used to collect data at the rate of $10 \mathrm{~Hz}$.

The raw GPS displacement measurements are first transformed into the local bridge coordinate system (BCS) using the rotation matrix, the vertical component is represented as the height variations above the mean sea level, and the horizontal displacements are obtained by taking a specific position as the datum.

The lateral, longitudinal, and vertical movements of the bridge in BCS during the $46 \mathrm{~h}$ trial are illustrated in Figure 2. It can be noted that the lateral direction contains more frequency information than the other two directions, as it is more vulnerable to ambient loadings. 

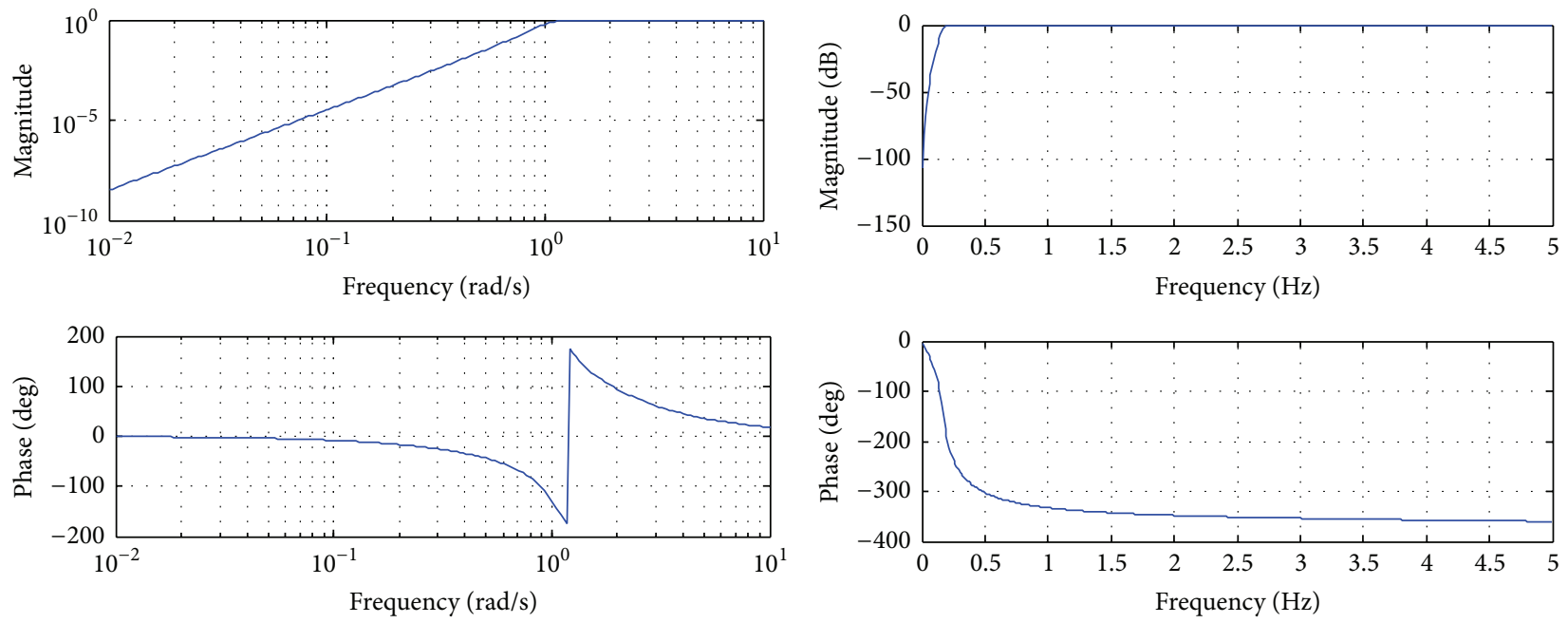

FIgURE 4: The corresponding analogue and digit filter.

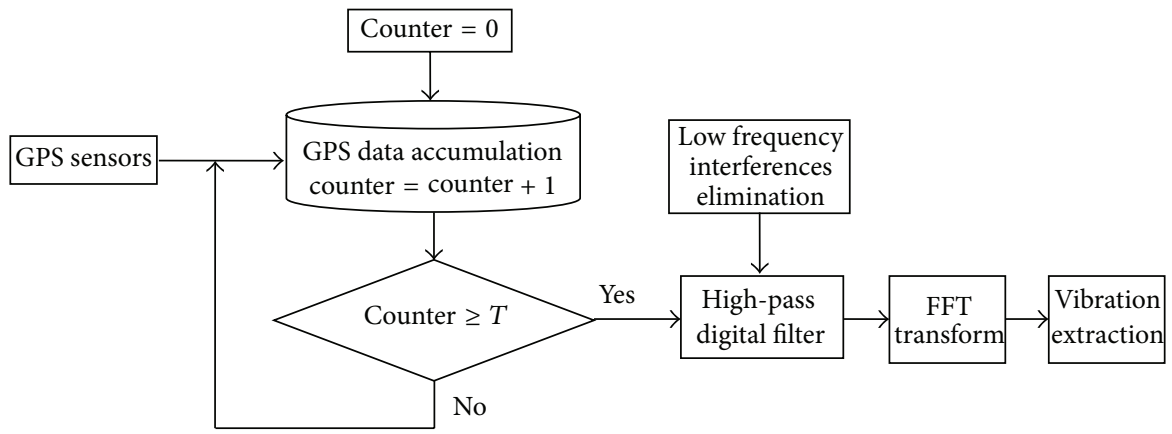

FIGURE 5: Flowchart for vibration frequencies extraction for the Forth Road Bridge.

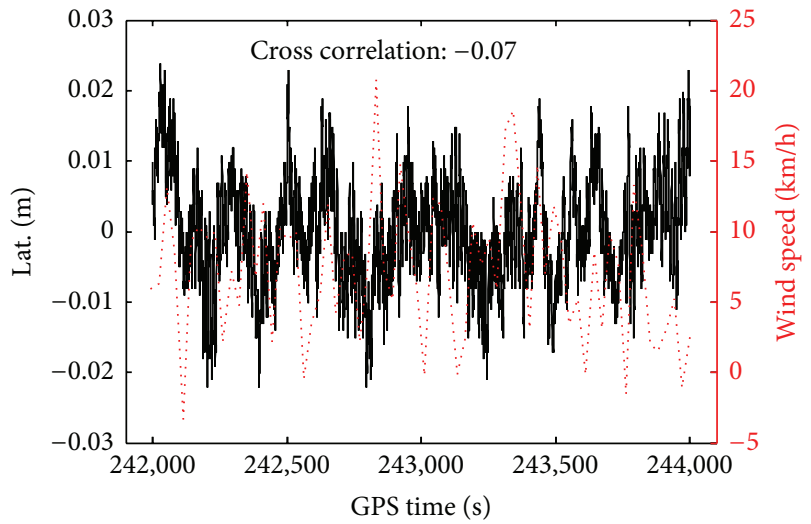

— Lat. displacement Lat. wind speed

Figure 6: Lateral displacement and wind speed.

Obvious systematic variations are shown in three directions that are affected by the temperature and wind according to the analysis in literature [20]. It is evident that lateral movements are most significant which reach an order of two meters; this is mainly caused by the ambient wind loadings, and the largest deflections occur in the second night due to the existence of high wind speeds. The height component of the bridge moves by an order of decimetres, and there exists a close relationship between the height response and ambient temperature variations and traffic loadings; in Figure 3, we can clearly see that a temperature change of about $5.5^{\circ} \mathrm{C}$ can be observed during the trial, and it evidently changes the vertical position of the bridge deck, especially the long-term dynamics. As expected, the longitudinal deflections are quite small, and the peak to peak movements are at the order of several centimetres. Three different deformation situations are considered to extract the vibration frequencies of the bridge in this paper, which will be discussed in detail in later sections.

\section{Data Processing Scheme}

3.1. Description of the Bridge Vibration Signal. The vibration signal of a bridge monitored by GPS can be expressed by

$$
y(n)=M(n)+D(n)+N(n),
$$

where $M(n)$ represents the low frequency interferences such as multipath error, atmospheric error, or clock error at $n$th observation epoch, among which multipath error is the main 


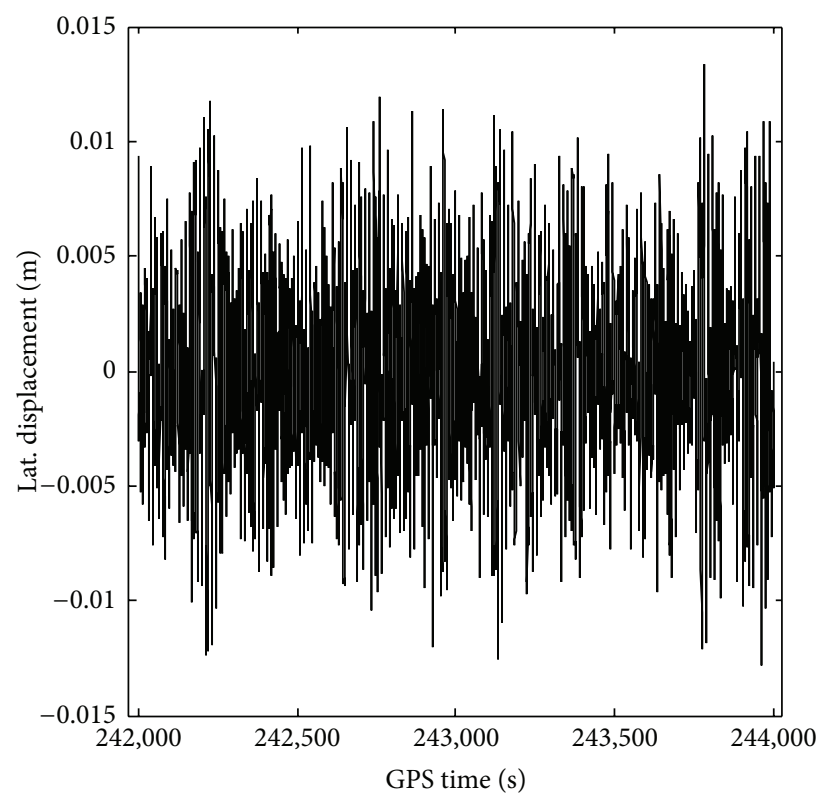

(a)

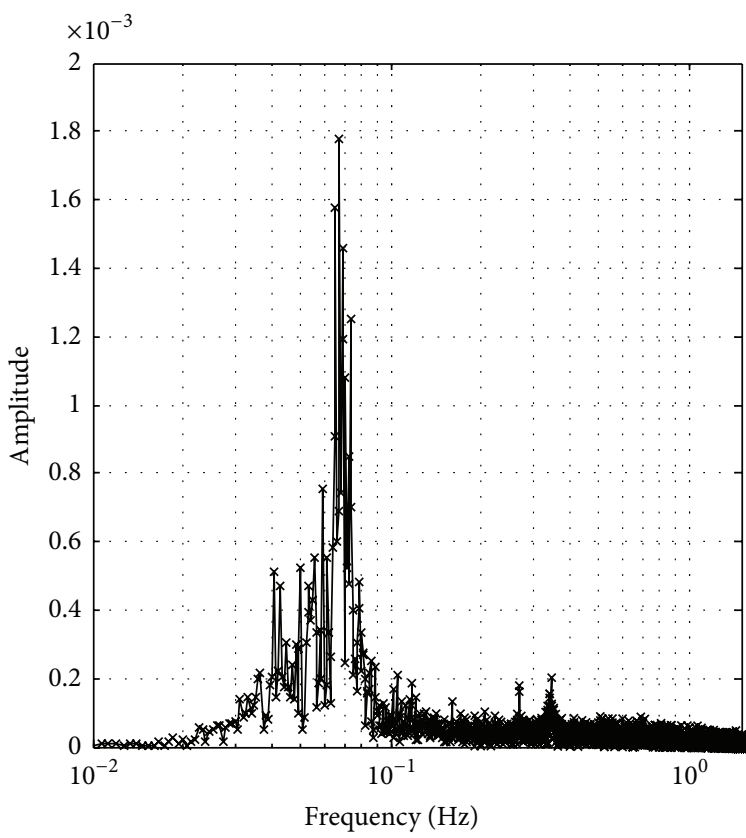

(b)

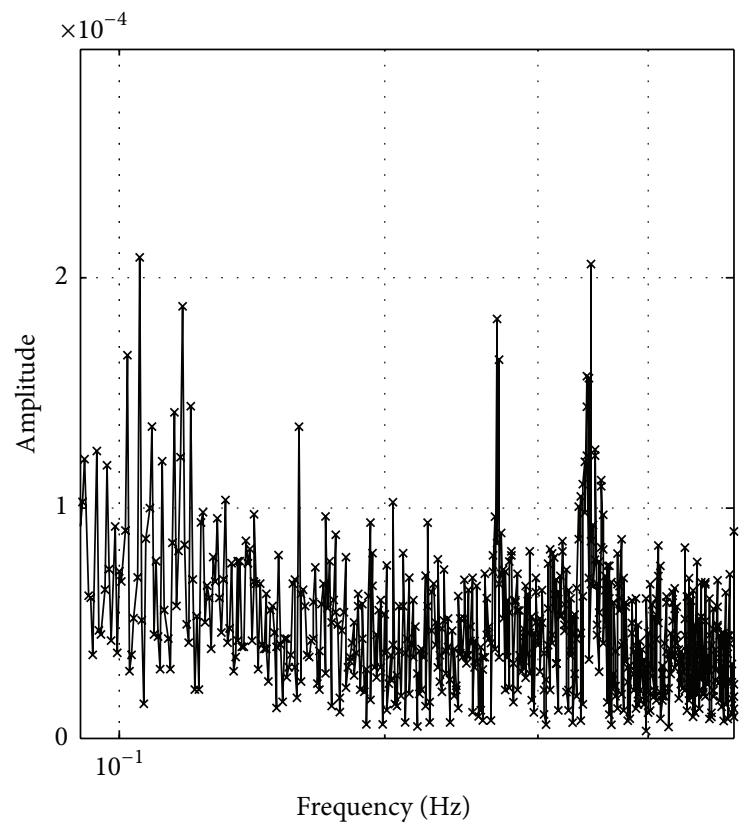

(c)

Figure 7: The filtered lateral displacements (a), corresponding vibration frequency ((b), full-scale band), and zoom-in of high frequency component (c).

part; $D(n)$ is the actual dynamic vibrations of the bridge and $N(n)$ is the noise [16]. To obtain the vibration frequencies of the bridge, low frequency deflections can be isolated using high-pass digital filter that can be designed according to the characteristics of the specific vibration signal, and Chebyshev high-pass digital filter is designed for the vibration frequencies extraction of the Forth Road Bridge in this paper.

3.2. Design of Chebyshev High-Pass Digital Filter. For Type I Chebyshev filter, the gain response as a function of angular frequency $\omega$ of $n$ th-order low-pass filter is equal to the absolute value of the transfer function $H_{n}(j \omega)$ :

$$
G_{n}(\omega)=\left|H_{n}(j \omega)\right|=\frac{1}{\sqrt{1+\varepsilon^{2} T_{n}^{2}\left(\omega / \omega_{0}\right)}}
$$

where $\varepsilon$ is the ripple factor, $\omega_{0}$ is the cut-off frequency, and $T_{n}$ is a Chebyshev polynomial of $n$th order. The order of 


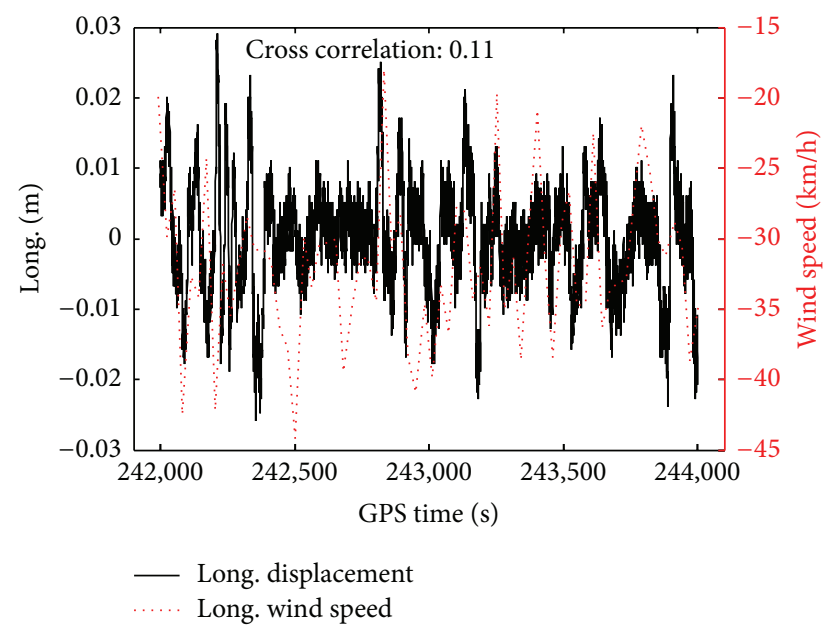

FIGURE 8: Longitudinal displacement and wind speed.

a Chebyshev filter is equal to the number of reactive components needed to realize the filter using analogue electronics [21].

The ripple is often given in $\mathrm{dB}$. Ripple in $\mathrm{dB}=$ $20 \log _{10} \sqrt{1+\varepsilon^{2}}$ so that a ripple amplitude of $3 \mathrm{~dB}$ results from $\varepsilon=1$. The transfer function is then given by

$$
H_{a}(s)=\frac{1}{2^{n}-1} \prod_{m=1}^{n} \frac{1}{\left(s-s_{p m}^{-}\right)},
$$

where $s_{p m}^{-}$are only those poles with a negative sign in front of the real term for the poles.

The bilinear transform is used to convert a transfer function $H_{a}(s)$ in the continuous-time domain to a transfer function $H_{d}(z)$ in the discrete-time domain. It maps positions on $j \omega$ axis, $\operatorname{Re}[s]=0$, in $s$-plane to the unit circle, $|z|=1$, in $z$-plane. The bilinear transform essentially uses this firstorder approximation and substitutes into the continuoustime transfer function [22], $H_{a}(s)$ :

$$
s \longleftarrow \frac{2}{T} \frac{z-1}{z+1} .
$$

That is,

$$
H_{d}(z)=\left.H_{a}(s)\right|_{s=(2 / T)((z-1) /(z+1))}=H_{a}\left(\frac{2}{T} \frac{z-1}{z+1}\right) .
$$

The low-pass Type I Chebyshev filter is transferred from analogue filter to digital filter by using the above bilinear transformation. Subsequently, the low-pass digital Type I Chebyshev filter is transferred into high pass by the following equation [23]:

$$
v^{-1}=-\frac{z^{-1}+\alpha}{1+\alpha z^{-1}},
$$

where

$$
\alpha=\frac{\cos \left(\left(\omega_{0}+\theta_{0}\right) / 2\right)}{\cos \left(\left(\omega_{0}-\theta_{0}\right) / 2\right)} .
$$

Equation (5) maps $z$-plane (low pass) to $v$-plane (high pass), and $\omega_{0}$ and $\theta_{0}$ are cut-off frequencies in $z$-plane and $v$-plane, respectively. The loads of the bridge are varying with different factors, such as wind speeds, traffic flow, and temperature variation; the optimal filter parameters can be determined considering the real deformation. By testing different data sets, the high-pass digital Type I Chebyshev filter with a sampling frequency of $20 \mathrm{~Hz}$ is good enough for the data processing of the bridge. In a real application, the filter is sampled into $10 \mathrm{~Hz}$. The critical frequency for pass band is 0.5 ; pass band attenuation is less than $0.8 \mathrm{~dB}$; the critical frequency for stopband is $0.025 \mathrm{~Hz}$; stopband attenuation is greater than $20 \mathrm{~dB}$. A high-pass digital Type I Chebyshev filter is designed with the above parameters (Figure 4).

3.3. The Scheme for Vibration Frequencies Extraction. The flowchart for vibration frequencies extraction is summarized in Figure 5. The real-time GPS displacement data sets are input into the designed high-pass digital filter introduced in Section 3.2, to eliminate the low frequency interferences. As a high-pass digital filter cannot be used in a real-time scenario, a GPS data accumulation counter is used to form a time series over a sliding window with a predefined length, to consider the different deformation situations, such as deformation during quiet period or busy period; a varied window length $T$ can be used, that is, $2000 \mathrm{~s}$ or $1000 \mathrm{~s}$, used in this paper. Finally, the vibration frequencies are obtained using the fast Fourier transform (FFT) algorithm.

\section{Vibration Frequencies Extraction}

4.1. Vibration Frequencies Extraction under Ambient Circulation Loading Conditions. In order to evaluate the safety of the large structures, such as long span bridges and highrise buildings, it is popular to extract the structural modal parameters such as natural frequencies, mode shapes, and damping ratios from GNSS measurements by using the ambient loadings. The Forth Road Bridge was operated under a heavy traffic flow in the daytime, especially at rush hour; the bridge deck was expected to move under the traffic loads. In this section, we are expected to extract the bridge dynamics under ambient circulation loading conditions; that is, the traffic flow and wind speed are not high.

In the following figure, data set of 2000 seconds (242001$244000 \mathrm{~s}$ ) for site $\mathrm{F}$ was used to characterize the bridge dynamics and extract the vibration frequencies. Figure 6 shows the lateral deflection time series and the corresponding wind speed data during the specific period; it is evident that the peak to peak deflection with the amplitude of about $4 \mathrm{~cm}$ is relatively small; this is due to existence of low wind speeds; the mean wind speed is $7.30 \mathrm{~km} / \mathrm{h}$ during the observation period; it shows low correlation with the wind speed. We can also see that very slow movements form a part of the lateral displacement time series, while the very slow vibration cannot indicate the natural frequencies of the bridge. In our paper, the high-pass filter introduced in Section 3.2 will be applied to the original displacement time series at $10 \mathrm{~Hz}$ 


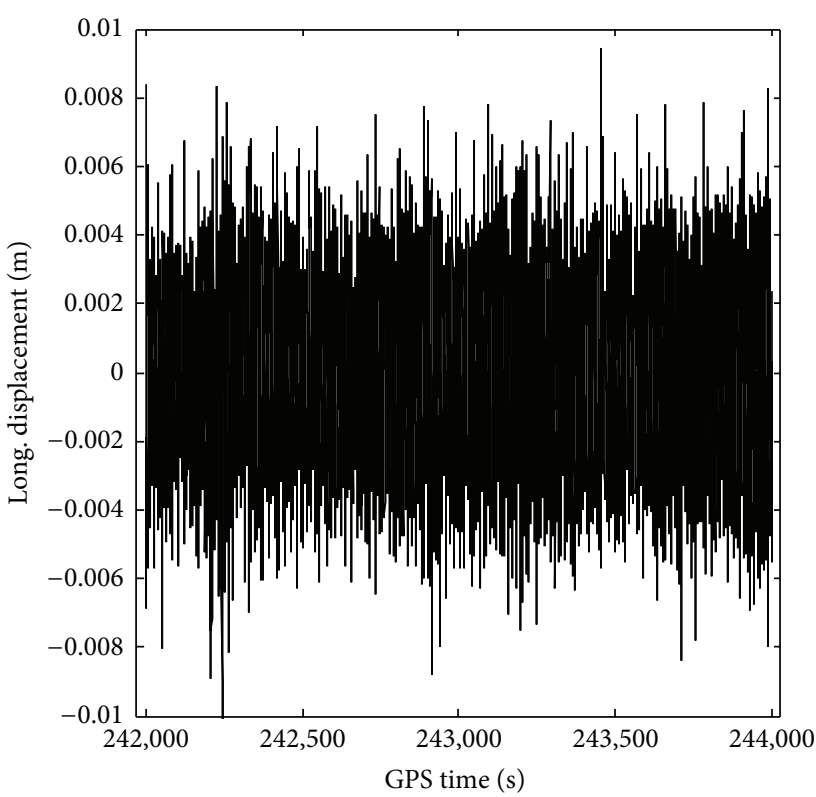

(a)

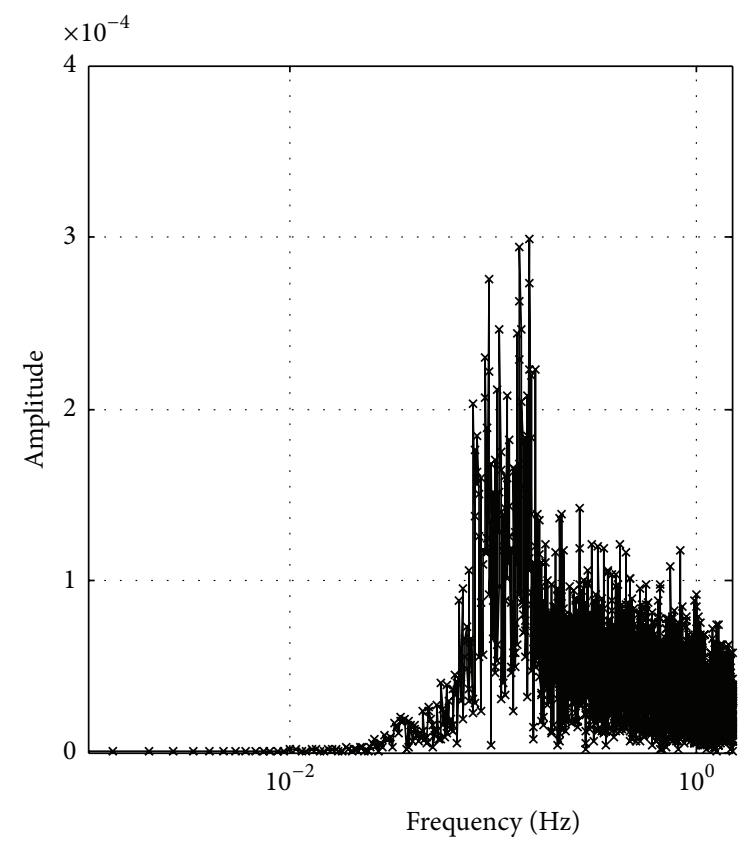

(b)

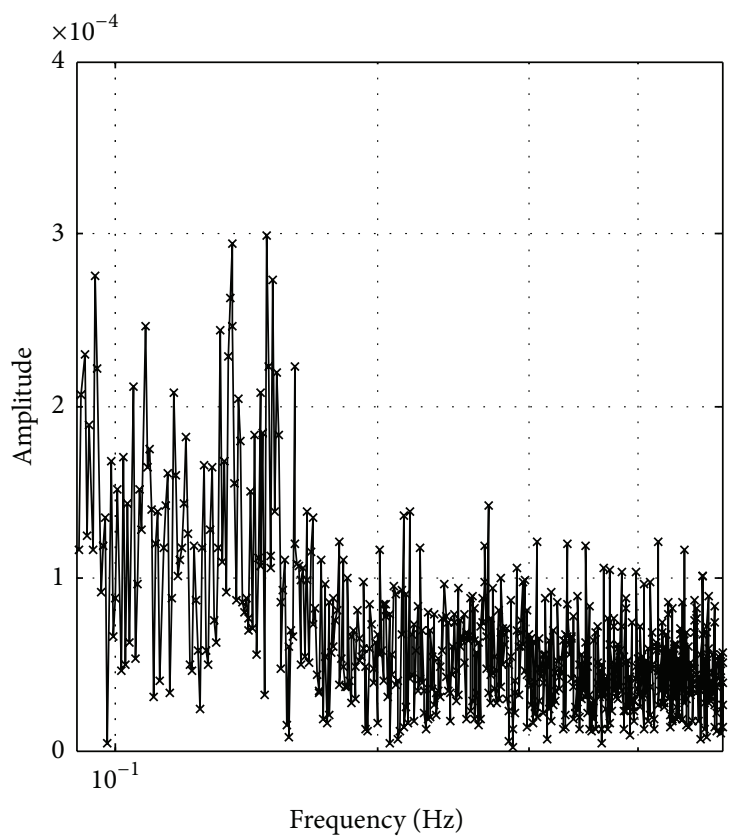

(c)

FiguRE 9: The filtered longitudinal displacements (a), corresponding vibration frequency ((b), full-scale band), and zoom-in of high frequency component (c).

firstly; then the output of the high-pass filtered data is used to obtain the vibration frequencies of the bridge. The filtered lateral movements and the corresponding frequencies are demonstrated in Figure 7; it can be seen that the amplitude of the dynamic displacements is small; a low frequency response peaked at $0.067 \mathrm{~Hz}$ is significant in the frequency spectra, which is mainly induced by the ambient wind loadings; five higher dominant frequencies with smaller amplitude can also be extracted from the spectra, the extracted frequencies are listed in Table 1, and this correlates well with our experience for such long span bridge.

The corresponding results for longitudinal deflections are demonstrated in Figure 8; as can be seen from the figure, the lateral response is constrained due to the stiffness of the bridge deck, and the bridge is not highly vulnerable to longitudinal motions, as can be validated from the low correlation between the longitudinal response and the wind speed. Figure 9 gives the corresponding natural frequencies 

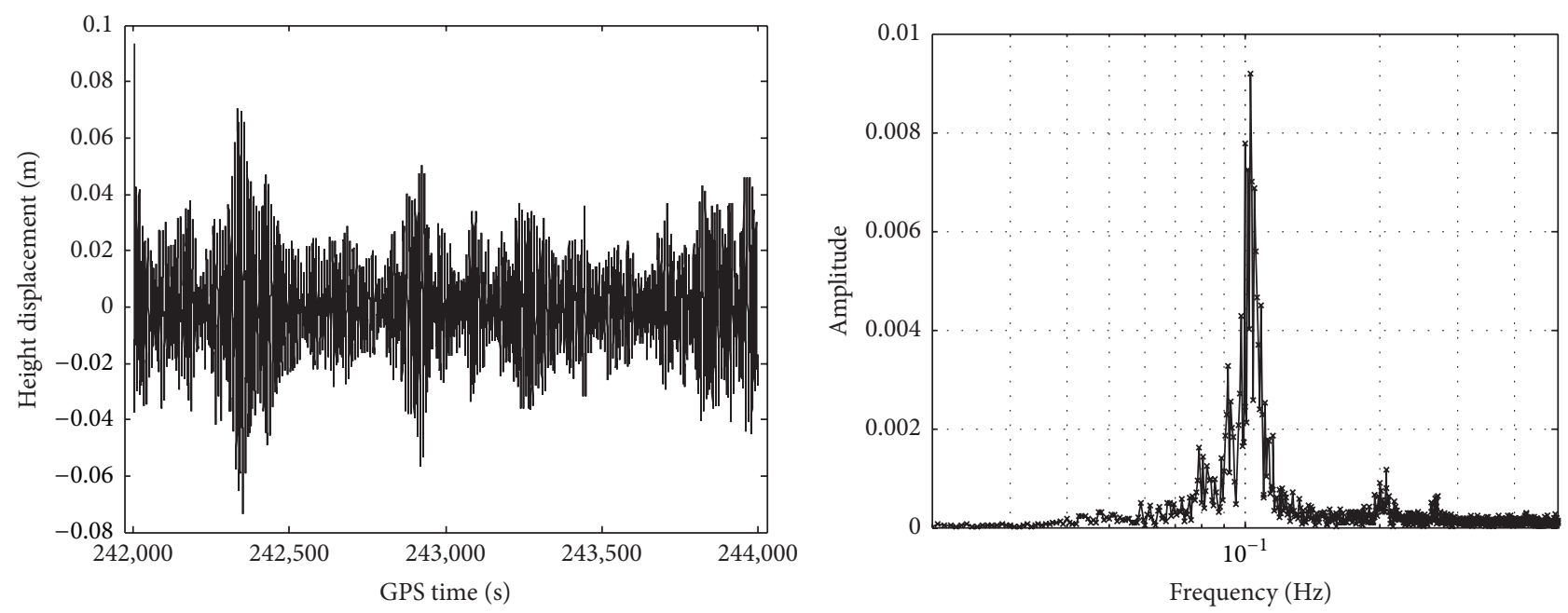

FIGURE 10: The filtered height displacements and corresponding frequencies.

TABLE 1: Vibration frequencies extracted from lateral GPS measurements ( $X$ direction of BCS).

\begin{tabular}{lccccccccc}
\hline Situations & \multicolumn{4}{c}{$\begin{array}{c}\text { Extracted frequencies }(\mathrm{Hz}) \\
\text { Common frequencies }\end{array}$} & \multicolumn{3}{c}{$\begin{array}{c}\text { Mean wind speed } \\
(\mathrm{km} / \mathrm{h})\end{array}$} \\
\hline Ambient circulation loading & 0.067 & 0.073 & 0.105 & 0.118 & 0.269 & 0.345 & 0.160 & 7.30 \\
\hline \multirow{2}{*}{ Strong wind (abrupt wind speed change) $)$} & 0.069 & 0.077 & 0.106 & 0.110 & 0.267 & 0.345 & - & 52.49 \\
& 0.068 & 0.071 & 0.105 & 0.110 & 0.270 & 0.344 & $0.097,0.101$ & 55.83 \\
\hline Two 40 t lorries passing & 0.064 & 0.073 & 0.103 & - & 0.268 & - & $0.132,0.147$ & 44.75 \\
\hline
\end{tabular}
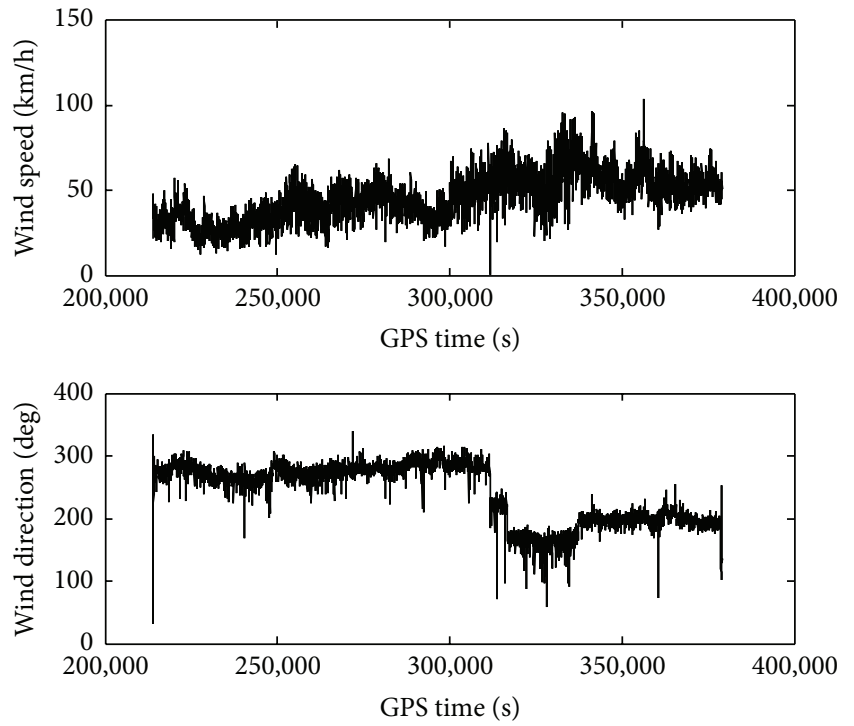

FIGURE 11: The wind speed and direction during the observation period.

extract from the filtered longitudinal movements; it can be seen that the longitudinal displacements are noisier than lateral displacements; the amplitude of the local frequency peak is not significantly large; thus the frequencies extracted from longitudinal movements are less accurate compared to the results extracted from lateral movements, and higher frequencies above $0.2 \mathrm{~Hz}$ cannot be detected from the filtered longitudinal displacement time series.

The filtered height deflections and the corresponding frequencies are shown in Figure 10, and it can be seen that the frequency response is significant at $0.103 \mathrm{~Hz}$, which is believed to be the natural frequency of the bridge; the amplitude of the frequency response at higher frequency band is obviously smaller than the first natural frequency response. It can be concluded that the vibration frequencies are successfully detected from the high-pass filtered displacement time series; that is, the frequencies extracted from the displacement time series in different direction are varied, and this can be explained by the fact that deflections in different direction are actually induced by different loading effects.

4.2. Vibration Frequencies Extraction during Wind Effect. During the observation period, the anemometer was used to record the wind speed and direction at $30 \mathrm{~s}$ sampling interval (Figure 11). As can be seen in Figure 11, the Forth Road Bridge was subject to high wind loadings during the whole observation session; the maximum wind speed exceeded $100 \mathrm{~km} / \mathrm{h}$; this will cause a large movement for the bridge deck and bridge tower. On the first day, the wind direction was almost perpendicular to the main axis of the bridge (Figure 12), while the wind direction was changed on the second day and the corresponding wind speed was also increased. 


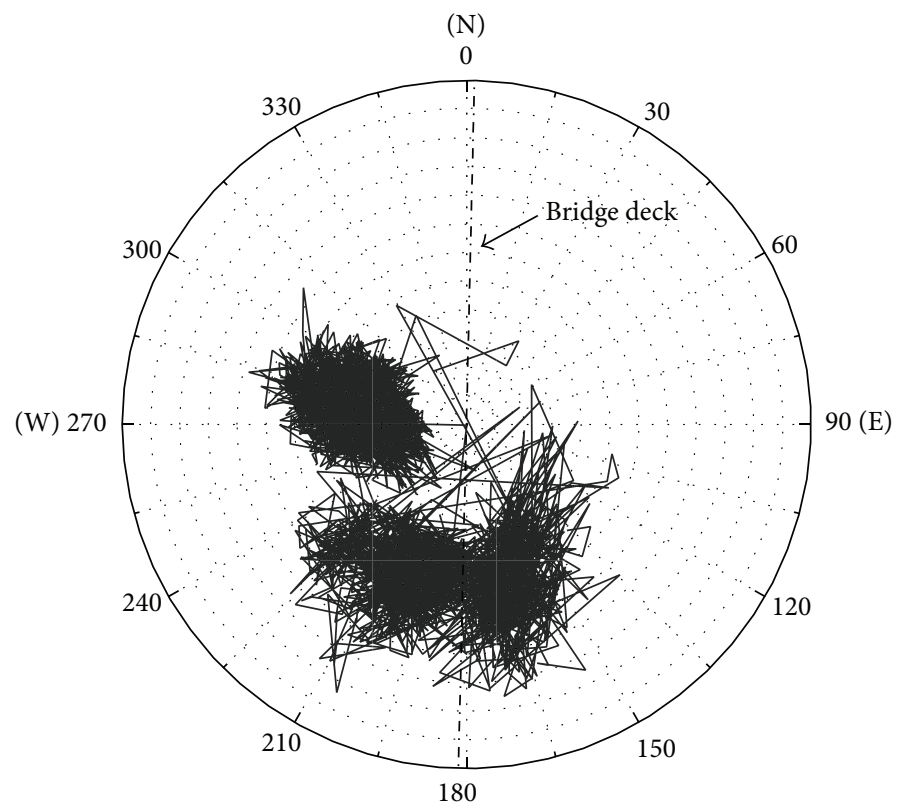

(S)

FIGURE 12: The wind direction variation during the observation period.

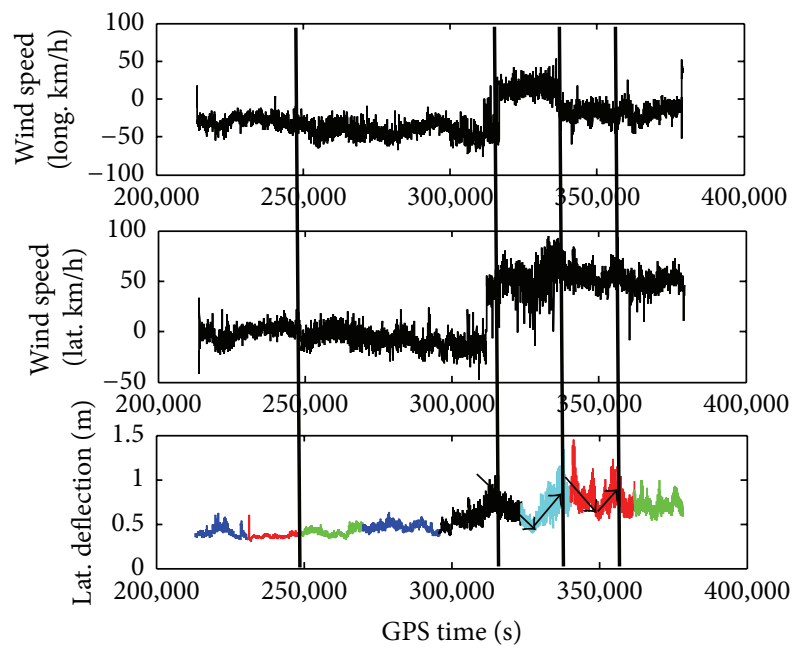

FIGURE 13: The wind speed resolved to BCS and the corresponding deflection.

Due to the stiffness of bridge, the longitudinal movements of the bridge deck are small, while the lateral movements are subject to wind action. The original wind speed data was first resolved to BCS for further analysis. Figure 13 shows wind speed in BCS and the corresponding lateral deflections; it can be seen that the lateral movements have good correlation with high wind speed; the sudden change of wind direction causes the peak vibration of the lateral deflection; once the wind speed keeps stable at a higher speed, the deflection becomes small as the heavy body of the bridge will be dragged down by the force of gravity, and the action of wind speed in lateral and longitudinal direction is cross-conditioning.

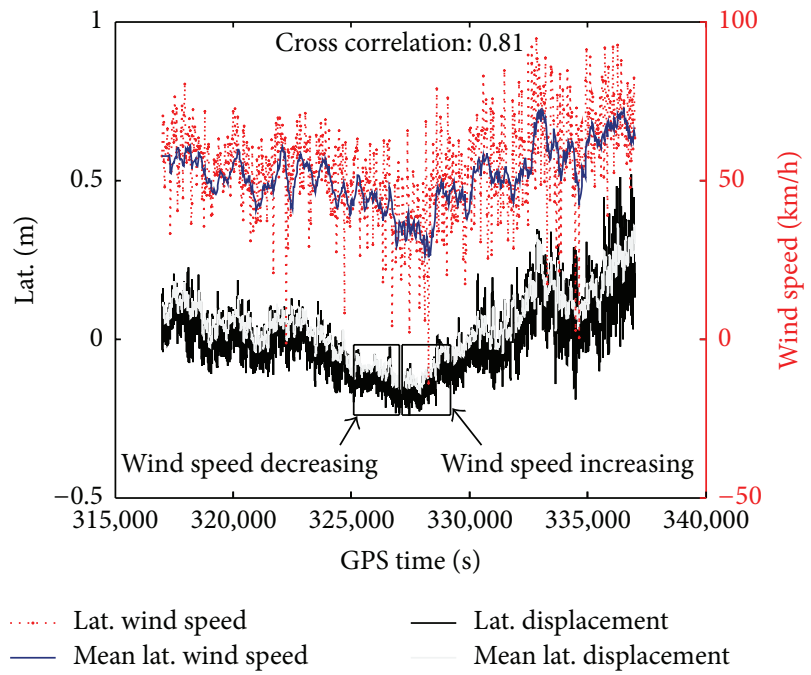

FIGURE 14: Lateral displacement and wind speed during the abrupt wind speed changing period.

In our paper, in order to characterize the interaction between the wind speed and deflection, we provide two wind speed changing situations for frequencies extraction using GPS, namely,

(a) wind speed decreasing period: 317001-327000 s;

(b) wind speed increasing period: 327001-337000 s.

Figure 14 illustrates lateral deflections and the corresponding wind speed during the selected wind speed abrupt changing period. It can be seen that there is high correlation between the deflection and wind speed ( 0.81 as shown in the figure), where the mean wind speed exceeds $50 \mathrm{~km} / \mathrm{h}$, and 


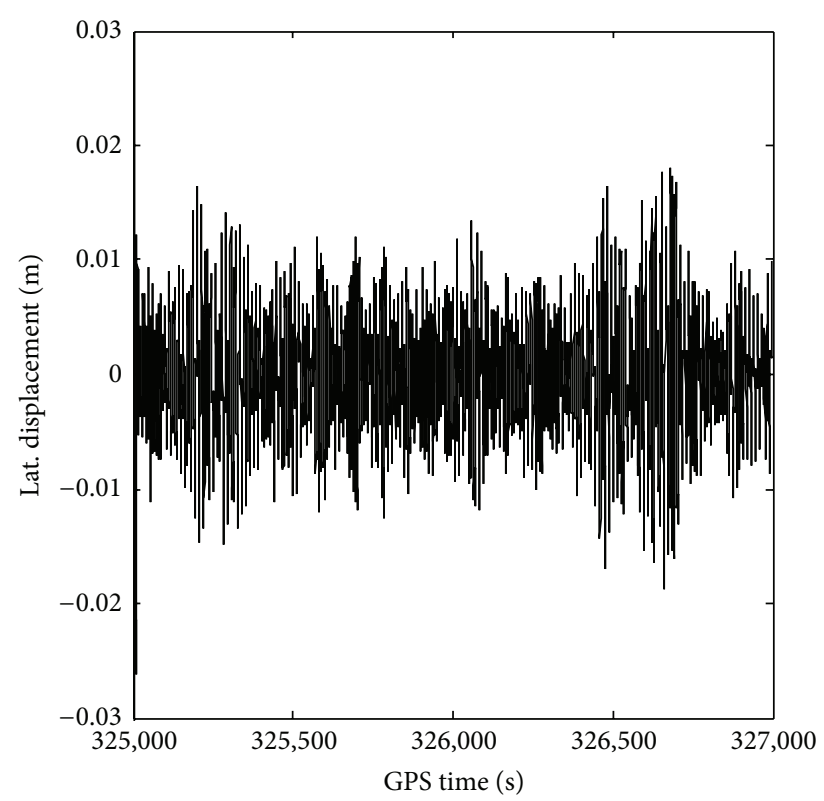

(a)

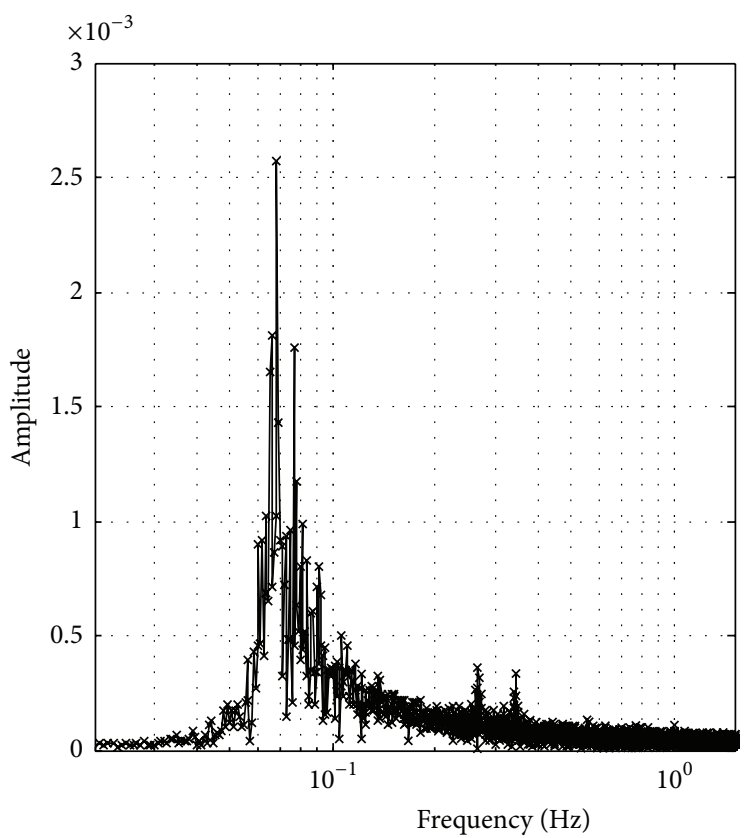

(b)

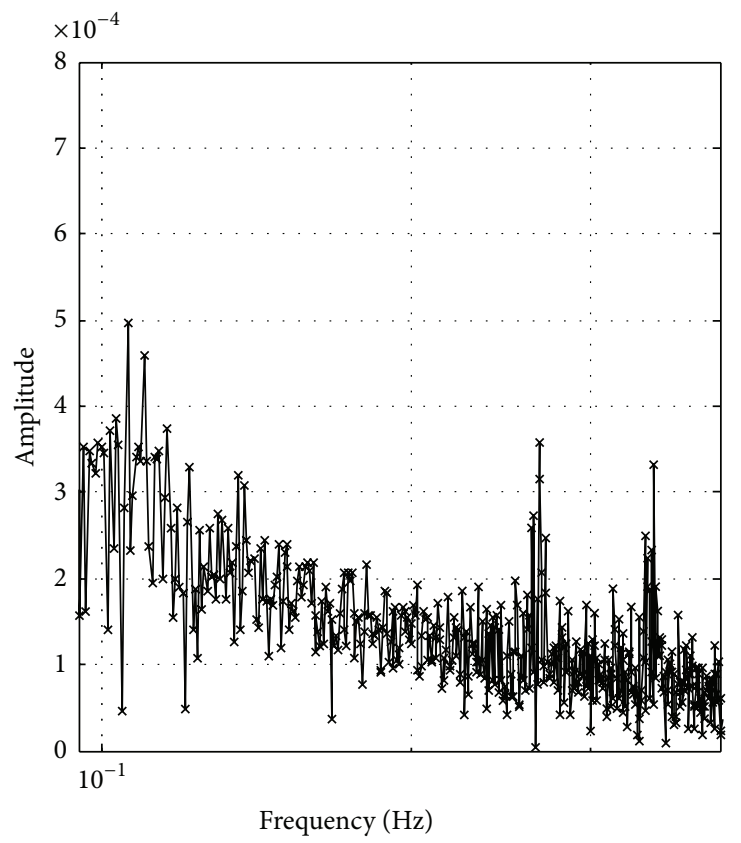

(c)

Figure 15: The filtered lateral displacements (a), corresponding vibration frequency ((b), full-scale band), and zoom-in of high frequency component (c) during the wind speed decreasing period.

the strong wind causes large movement along lateral direction for the bridge deck.

The lateral deflections contain very slow movements which are beyond the natural frequency band; the bilinear Chebyshev high-pass filter was applied to the original displacement time series. The filtered lateral displacements and corresponding vibration frequencies under ambient wind loadings are shown in Figures 15 and 16; the extracted local vibration frequencies less than $5 \mathrm{~Hz}$ using GPS displacement under two different wind loading conditions show similar characteristics above $0.1 \mathrm{~Hz}$ frequency band; this indicates that no significant changes occur in the structural characteristics, while the frequency response extracted from case (b) contains a local peak at $0.097 \mathrm{~Hz}$ which is mainly caused by wind conditions. The low frequency colour noise is still evident in the filtered displacement time series; thus the identification of the dominant frequencies becomes difficult. The amplitude of the high frequency response at $0.44 \mathrm{~Hz}$ 


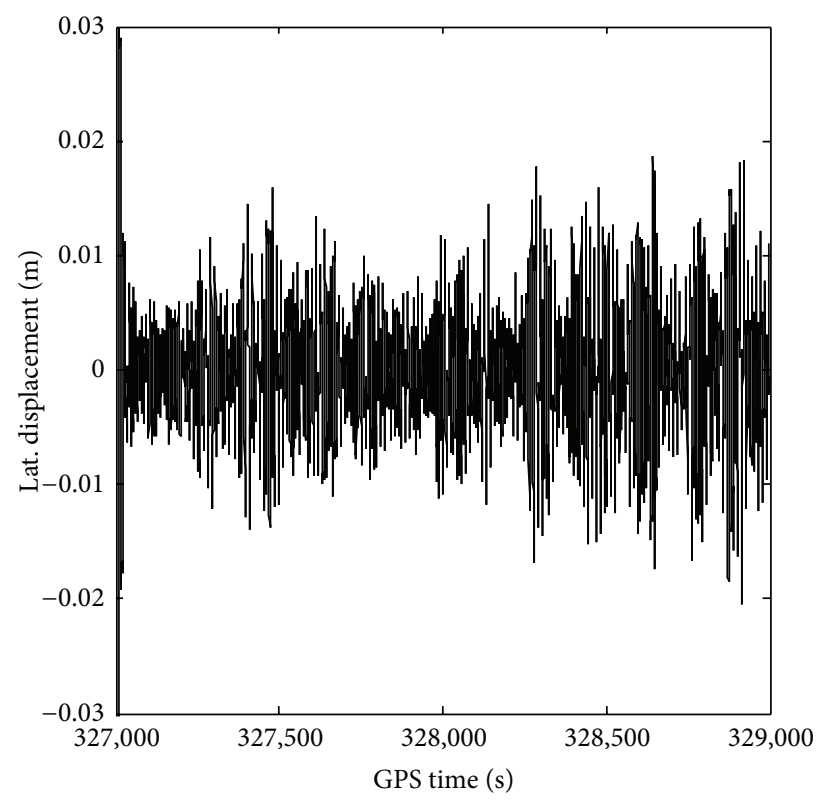

(a)

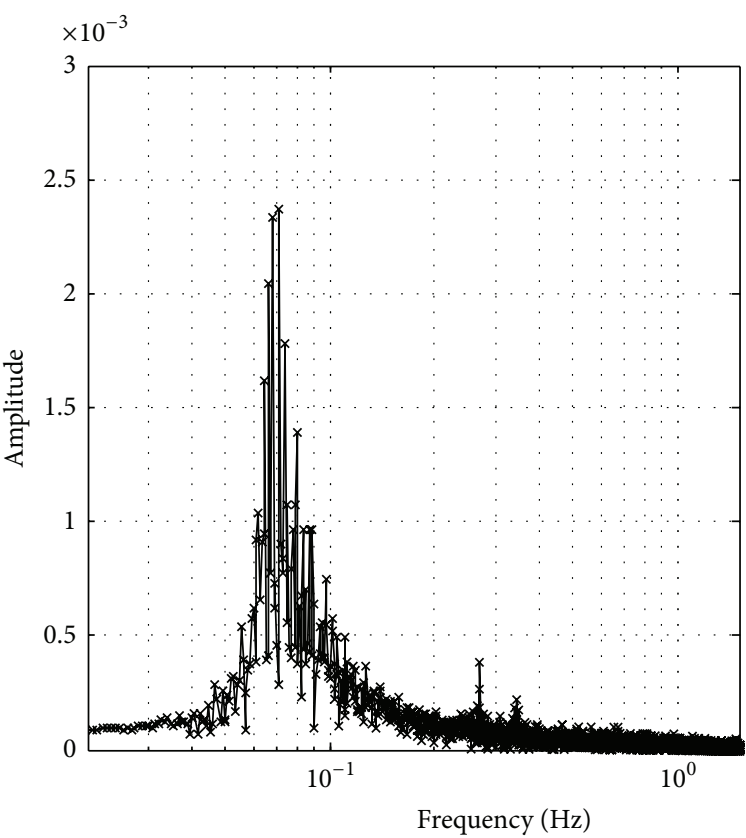

(b)

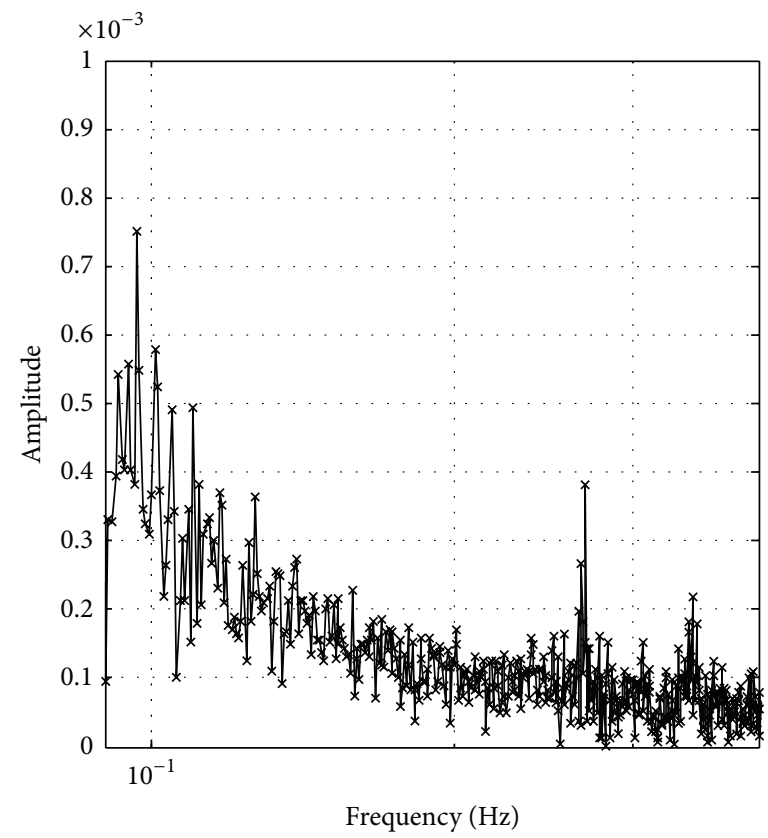

(c)

Figure 16: The filtered lateral displacements (a), corresponding vibration frequency ((b), full-scale band), and zoom-in of high frequency component (c) during the wind speed increasing period.

during the wind speed increasing period is larger than that of the response occurring during the wind speed decreasing period.

The longitudinal displacement measurements during the specific observation period are demonstrated in Figure 17; it can be noted that the wind speed data is noisy, and the correlation between the longitudinal response and the wind data is low. The excitation of longitudinal response is actually a combination of wind loadings, traffic loadings, and thermal effects. The filtered results are shown in Figures 18 and 19; the peak amplitude of the vibration is quite small, of the order of $\pm 5 \mathrm{~mm}$; the frequency characteristics are quite different from that of lateral response; the detected vibration frequency is lower than $0.3 \mathrm{~Hz}$, and the dominant frequency response is significant at $0.129(0.126 \mathrm{~Hz}$ for wind increasing period), 0.134 , and $0.151 \mathrm{~Hz}$; the low frequency noise is still evident in the filtered displacement time series. 


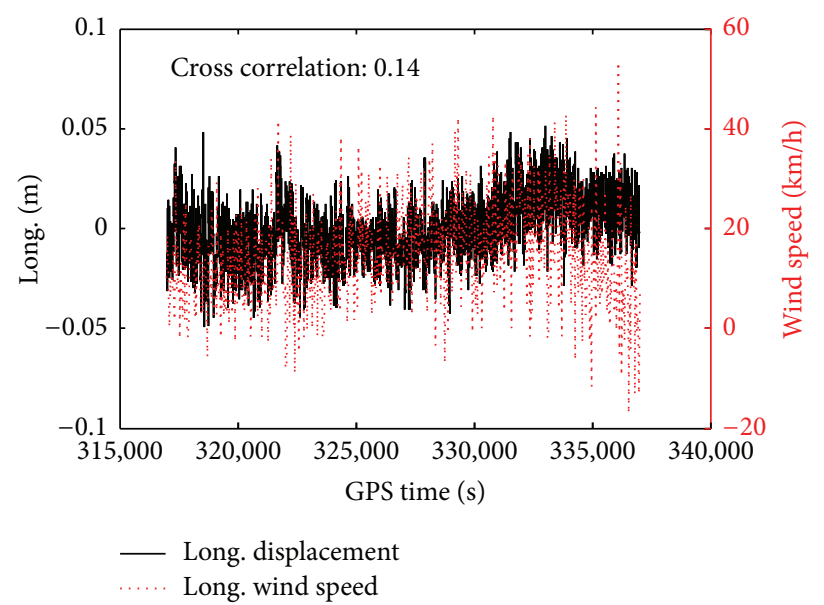

FIGURE 17: Longitudinal displacement and wind speed.
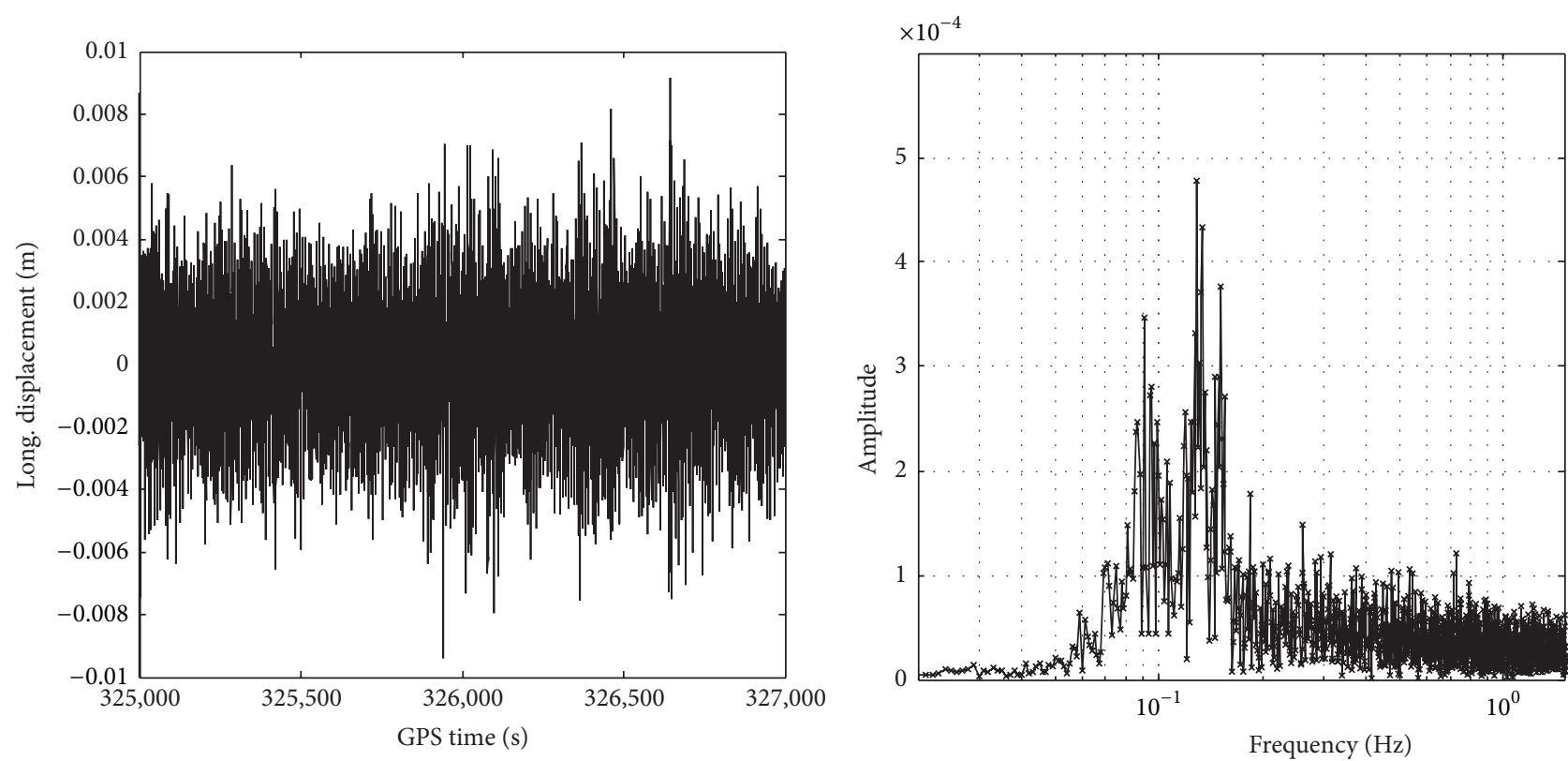

FIGURE 18: The filtered longitudinal displacements and corresponding frequencies during the wind speed decreasing period.

The corresponding filtered height response is shown in Figures 20 and 21; compared to the horizontal response, the amplitude of the height dynamic displacement is obviously larger, which is due to existence of traffic loadings. As can be seen from the frequency spectrum, a significant amplitude peak at $0.102 \mathrm{~Hz}$ is detected using the height displacement time series, while a slightly different frequency at $0.104 \mathrm{~Hz}$ is observed for the wind speed increasing period; two higher frequency peaks can be detected for both wind loading conditions. The vibration frequencies extracted from height displacement time series seem to be clearer than the frequencies extracted using horizontal displacement time series; this demonstrates the superiority of using height deflections for monitoring the frequency response.

4.3. Vibration Frequencies Extraction of the Lorry Loading. The Forth Road Bridge has experienced increased traffic loadings since the opening of the bridge, and the heavy traffic loadings play an important role in the bridge deformation, especially for the height deflections. During the second night, a specific trail with two $40 \mathrm{t}$ lorries running on the bridge was carried out to evaluate the pattern of deflection; the bridge was closed off to other traffic during the trial; in addition, the lorries travelled at a low speed manner; the running speed was about $32 \mathrm{~km} / \mathrm{h}$. The travelling period used for analysis in this paper was described as follows:

(a) One lorry ran from north to south.

(b) One lorry ran from south to midspan on the west side and stopped and then the other lorry moved north to south.

The data set duration is $1000 \mathrm{~s}$ (349705-350704 s); the experienced wind speed had subsided slightly during the observation period. The absolute deflections for site F during 

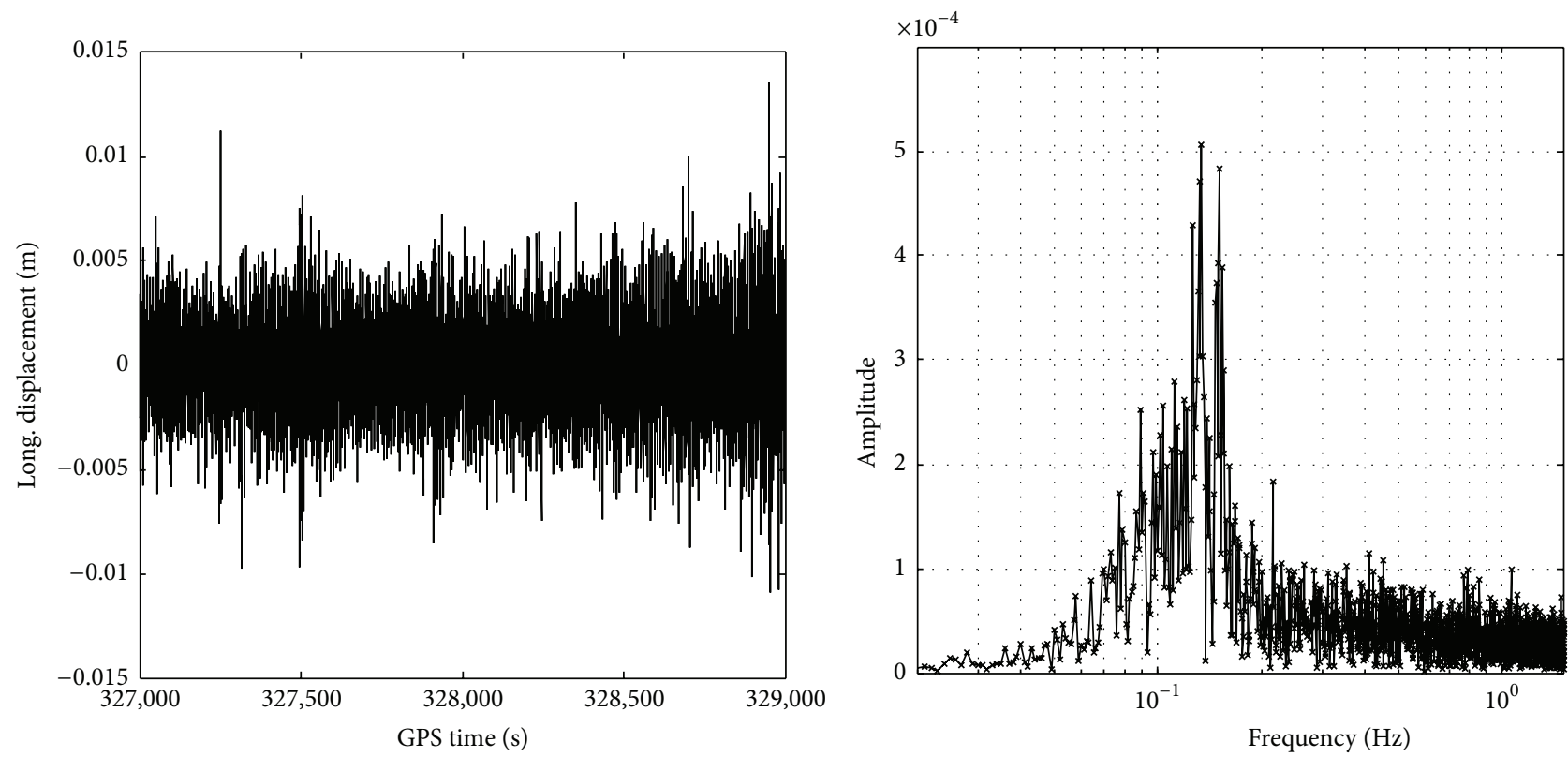

FIGURE 19: The filtered longitudinal displacements and corresponding frequencies during the wind speed increasing period.
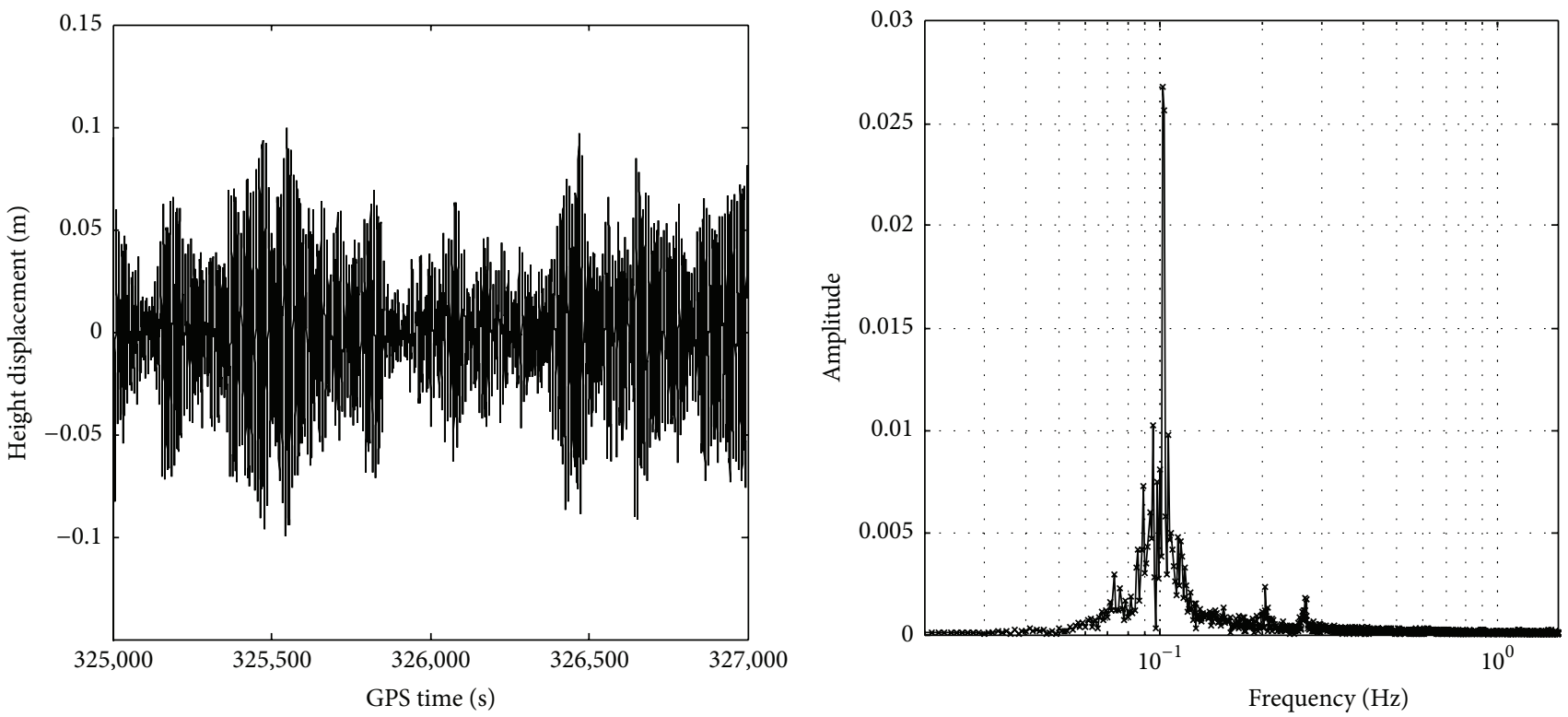

FIGURE 20: The filtered height displacements and corresponding frequencies during the wind speed decreasing period.

the lorries passing were illustrated in Figure 22; it can be seen that the movements in different direction are deflected by different magnitudes, among which the height component experienced the largest deflections, of the order of $\pm 0.3 \mathrm{~m}$. The bridge experienced downward deflections as the lorry travelled approaching the midspan of bridge, and upward movements were observed when the lorry moved away; this is due to existence of the elastic suspension cable which pulled up the bridge main span. The GPS measured deflections match well with that of FEM predicted results, and occurrence of such bridge deflection can be well explained by the lorries' mass. It should be noted that the patterns of the lateral movements do not completely coincide with height movements; actually the lateral movements are partially induced by the ambient wind loadings.

To extract the vibration frequencies during the lorry passing period, the original displacement time series was first filtered using the bilinear Chebyshev high-pass filter; the resulting dynamic lateral deflections and extracted frequencies are illustrated in Figure 23; the amplitude of the dynamic displacements exceeds $2 \mathrm{~cm}$; it can be seen that the high frequency response at $0.345 \mathrm{~Hz}$ is not significant from frequency spectrum, while the frequency response at 0.064 and $0.073 \mathrm{~Hz}$ is still the most significant. Compared to 

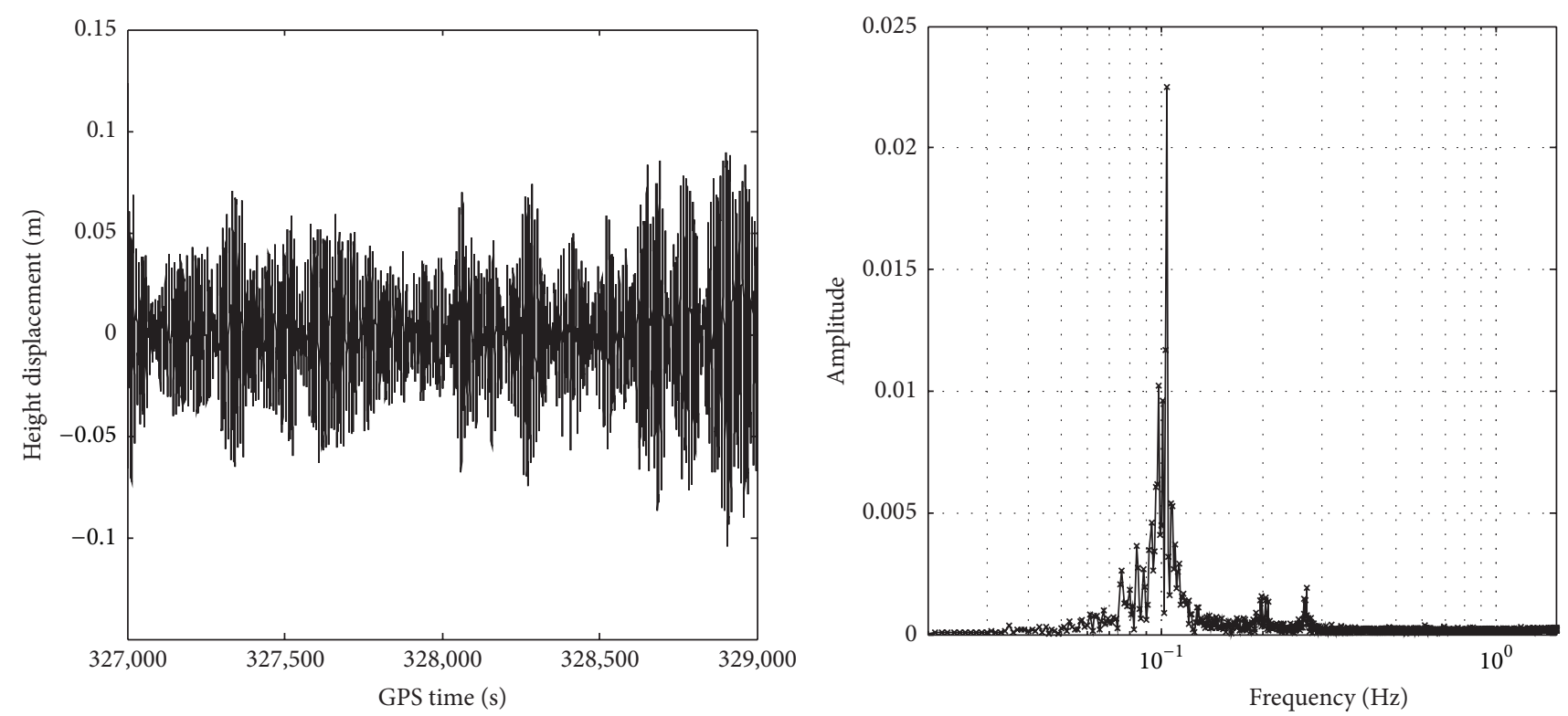

FIGURE 21: The filtered height displacements and corresponding frequencies during the wind speed increasing period.

the deformation induced by the low wind loadings, the frequency extraction under high wind loadings becomes clearer.

The filtered longitudinal displacements and extracted frequencies are demonstrated in Figure 24; it can be seen that the amplitude of the dynamic displacements is below $1 \mathrm{~cm}$, and the dynamic response is actually not highly affected by the lorry loading; the frequency characteristic of the response is similar to the response under ambient circulation loading; expect one suspected high frequency at $0.332 \mathrm{~Hz}$ detected from the displacement time series; indeed, the high frequency response is vanished due to the existence of high frequency noise.

The corresponding height dynamic displacements and the extracted frequencies are shown in Figure 25; the amplitude of the dynamic deflections exceeds $0.1 \mathrm{~m}$; the most significant frequency response is still at $0.103 \mathrm{~Hz}$; it seems that no significant frequency deviation occurs from the frequency spectrum.

4.4. Extracted Frequencies Comparisons. As previously analysed, we have successfully extracted the vibration frequencies of the bridge under different loading conditions, that is, the ambient circulation loading, strong wind speed sudden changing period, and the specific trial with two $40 \mathrm{t}$ lorries passing the bridge. The results of the extracted frequencies are listed in Tables 1-3. By comparing the results, we can see that the vibration frequencies extracted from the GPS measurements in different direction are varied greatly from each other. Due to the bridge deck stiffness of the bridge deck, the movement along the bridge main axis is small, and low frequency noise can be obviously observed in the longitudinal displacement time series, which makes the frequencies extraction more difficult using the peak-picking approach, and the extracted frequencies show different characteristic.
By making a detailed comparison of Tables 1 and 3, we can find that two common frequencies can be extracted from both lateral displacement time series and height displacement time series though the dynamics are induced by different loading effects, that is, 0.105 and $0.269 \mathrm{~Hz}$ (slightly different under different ambient loading conditions), so it may be deduced that the two frequencies are the natural frequencies of the bridge. While the other computed frequencies may not indicate the modal characteristics, they mainly indicate excitation frequencies; these frequencies are significant only if they approach modal frequencies with much energy. On the other hand, it should be noted that the extracted frequencies actually varied under different loadings; this will greatly benefit the online damage identification process, because the frequency response is an indicator of structural behaviour. We can also find that height frequency responses are relatively stable for they are mainly affected by the traffic loadings and thermal effects.

\section{Conclusions}

This paper investigated a GPS deformation trial carried out on the Forth Road Bridge in Scotland. It shows that GPS can capture the absolute 3D deflections of the bridge accurately at a $10 \mathrm{~Hz}$ sampling rate. The results have shown that lateral movements highly correlate with the ambient wind loading as the wind speed is high, while the height deflections are mainly caused by the traffic loading and thermal effect; the movement along the bridge main axis is small due to the stiffness of the bridge deck.

To demonstrate the frequency response under different loadings, three different ambient loading conditions are considered, namely, the ambient circulation loading, strong wind abrupt speed changing period, and the specific trial with two $40 \mathrm{t}$ lorries passing the bridge. A bilinear Chebyshev 


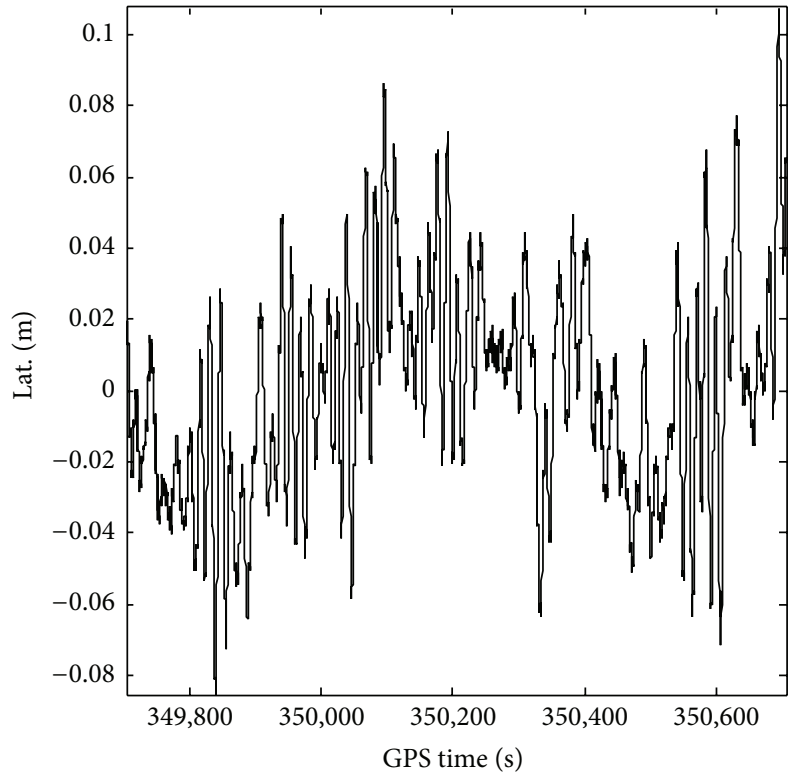

(a)

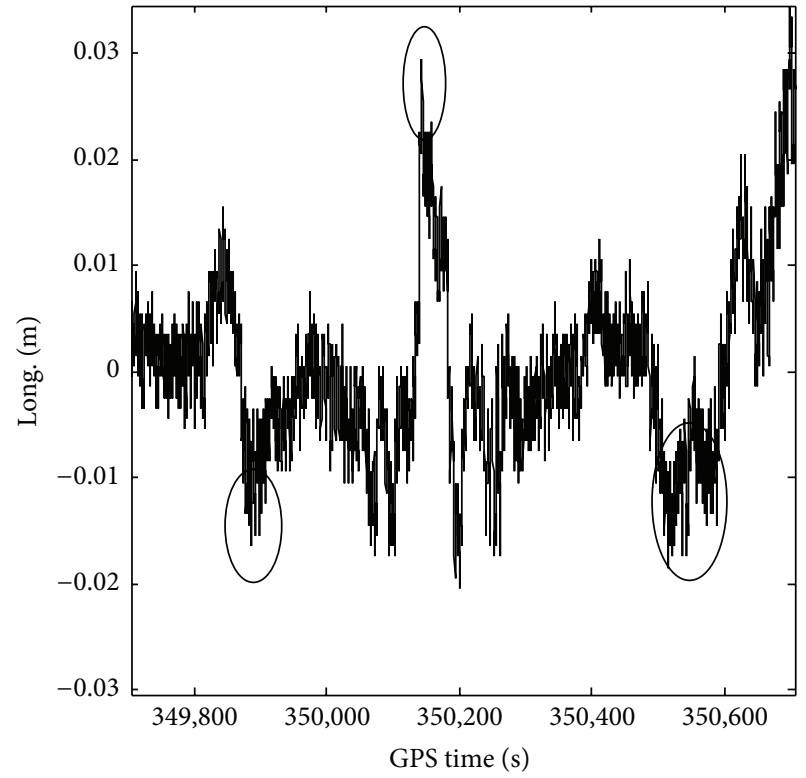

(b)

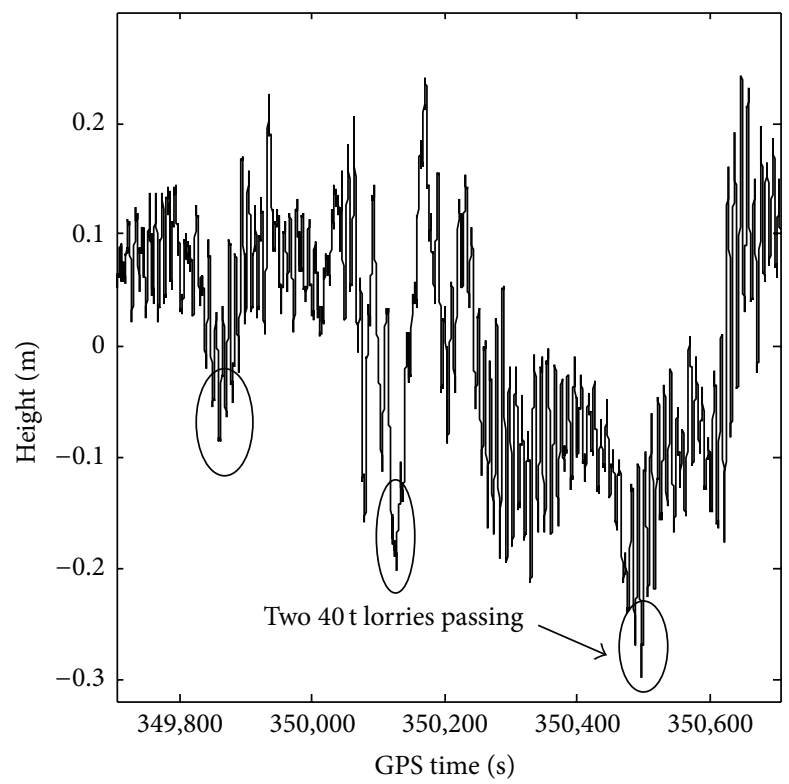

(c)

FIgURE 22: Absolute deflections of bridge site F during the two $40 \mathrm{t}$ lorries passing.

TABLE 2: Vibration frequencies extracted from longitudinal GPS measurements ( $Y$ direction of BCS).

\begin{tabular}{lcccccccc}
\hline Situations & & \multicolumn{4}{c}{ Extracted frequencies $(\mathrm{Hz})$} & \multicolumn{2}{c}{$\begin{array}{c}\text { Mean wind speed } \\
(\mathrm{km} / \mathrm{h})\end{array}$} \\
\hline Ambient circulation loading & \multicolumn{2}{c}{ Common frequencies } & & Distinct frequencies & 31.96 \\
\hline Strong wind (abrupt wind speed change) & 0.091 & - & 0.129 & 0.134 & 0.151 & $0.184,0.262$ & 12.21 \\
& - & - & 0.126 & 0.134 & 0.151 & 0.216 & 16.46 \\
\hline Two 40 t lorries passing & & 0.106 & 0.129 & 0.131 & 0.150 & $0.172,0.332$ & 13.34 \\
\hline
\end{tabular}



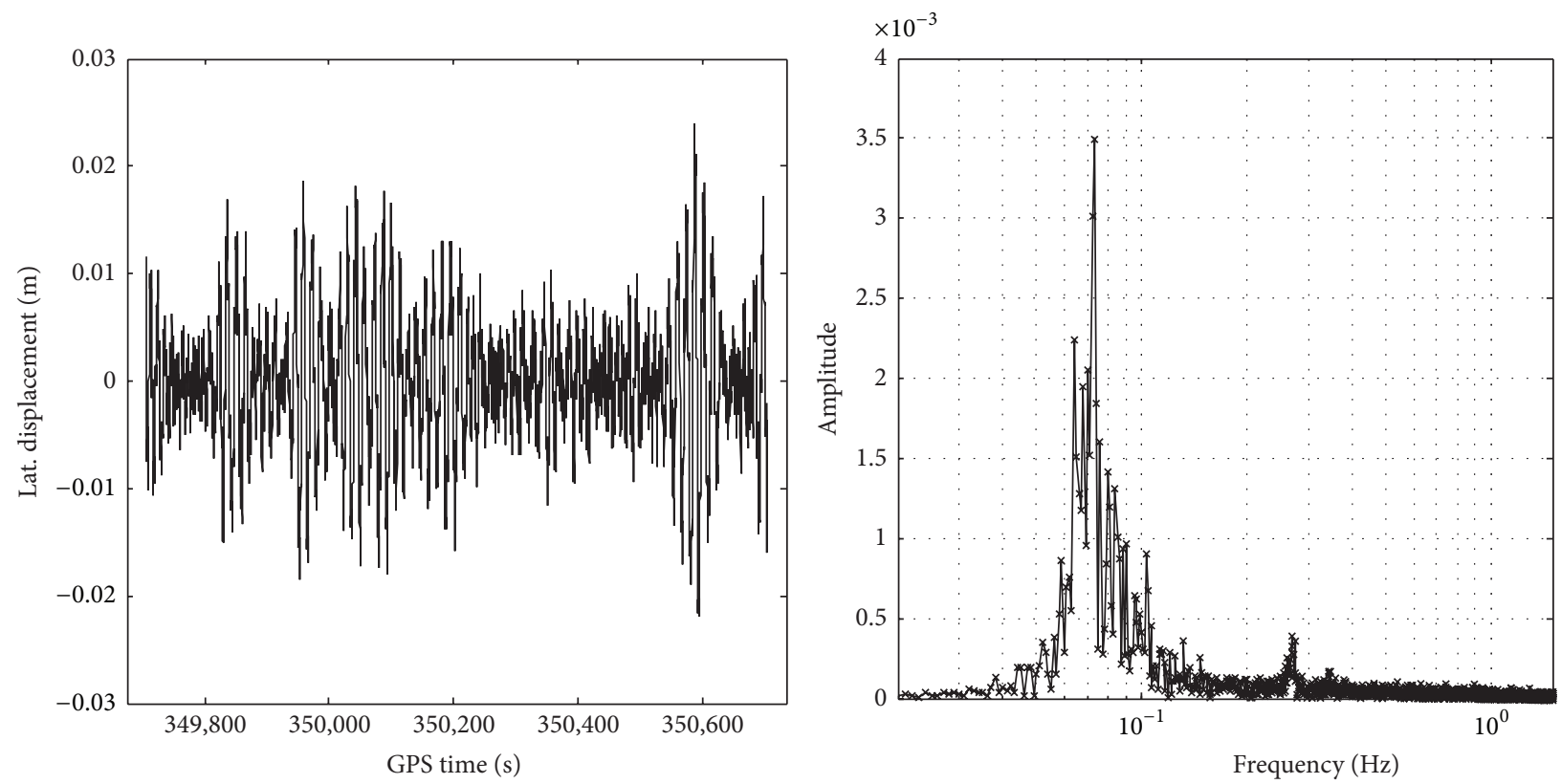

FIGURE 23: The filtered lateral displacements and corresponding frequencies.
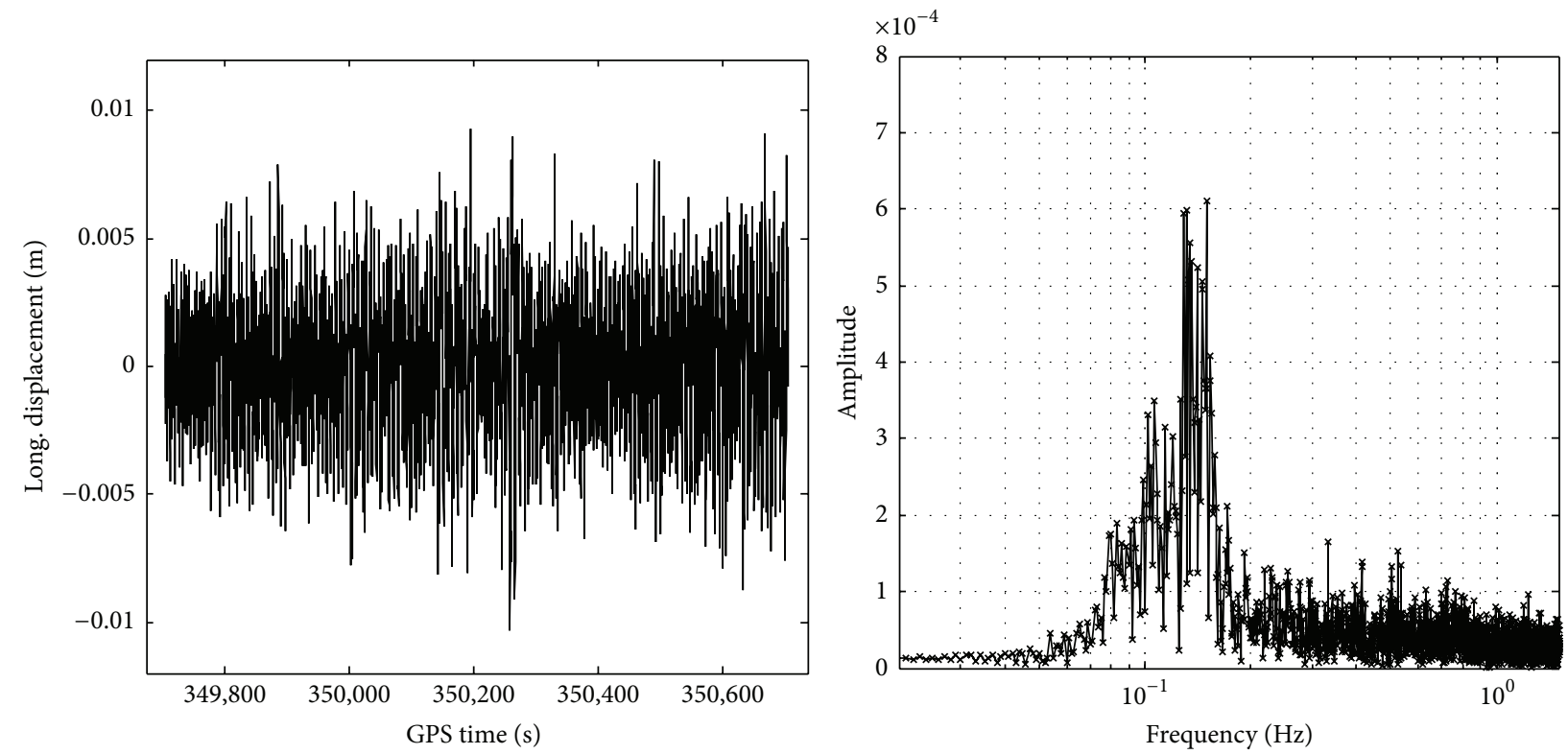

FIGURE 24: The filtered longitudinal displacements and corresponding frequencies.

TABLE 3: Vibration frequencies extracted from height GPS measurements ( $U$ direction of BCS).

\begin{tabular}{|c|c|c|c|c|c|}
\hline Situations & & Extracte & encies ( & & Mean wind speed $(\mathrm{km} / \mathrm{h})$ \\
\hline Ambient circulation loading & 0.092 & 0.103 & 0.207 & 0.270 & - \\
\hline Strong wind (abrupt wind speed change) & 0.095 & 0.102 & 0.205 & 0.268 & - \\
\hline 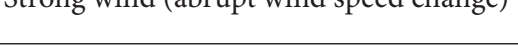 & 0.098 & 0.104 & 0.204 & 0.270 & - \\
\hline Two $40 \mathrm{t}$ lorries passing & 0.096 & 0.103 & 0.202 & 0.268 & - \\
\hline
\end{tabular}



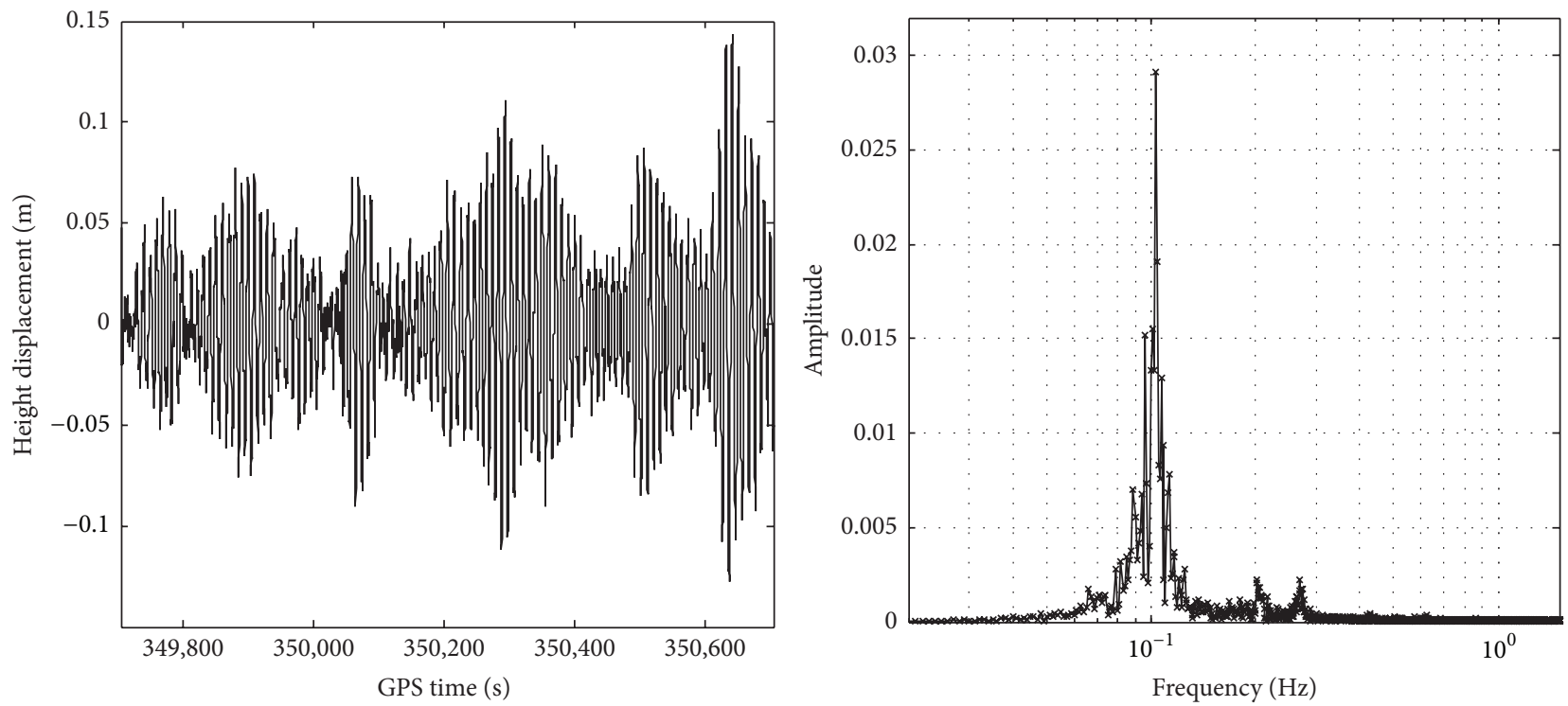

FIGURE 25: The filtered height displacements and corresponding frequencies.

high-pass filter was presented and applied to the original displacement time series to remove the very slow movements, which do not locate in the structural natural frequency band. The FFT algorithm was applied to the filtered displacement time series, and the vibration frequencies are extracted using the peak-picking approach. The results show that the frequency responses in different directions vary greatly with each other, and the frequency responses at 0.105 and $0.269 \mathrm{~Hz}$ extracted from lateral displacement time series correlate well with the data using height displacement time series; the natural frequencies change slightly under different ambient loadings. The approach introduced in this paper can be well applied for the future online bridge monitoring; the structural deterioration and failure will be monitored using the real GPS data in real time, and the frequency response becomes the basis to evaluate the behaviour of the bridge.

\section{Conflict of Interests}

The authors declare that there is no conflict of interests regarding the publication of this paper.

\section{Acknowledgments}

The data acquisition was sponsored by the Forth Road Bridge. The other colleagues of the University of Nottingham are acknowledged. This work was partially supported by the Fundamental Research Funds for the Central Universities (no. 2014ZDPY15), the Program for New Century Excellent Talents in University (no. NCET-13-1019), a project funded by the Priority Academic Program Development of Jiangsu Higher Education Institutions, and the Cooperative Innovation Centre of Jiangsu Province.

\section{References}

[1] M. Leach, M. Hyzak, and S. Horoschak, "Validation and analysis of results from a bridge motion monitoring experiment," in Proceedings of the 49th Annual Meeting of the Institute of Navigation: Future Global Navigation and Guidance, pp. 519527, Cambridge, Mass, USA, June 1993.

[2] J. W. Lovse, W. F. Teskey, G. Lachapelle, and M. E. Cannon, "Dynamic deformation monitoring of tall structure using GPS technology," Journal of Surveying Engineering, vol. 121, no. 1, pp. 35-40, 1995.

[3] A. Wieser and F. Brunner, "Analysis of bridge deformations using continuous GPS measurements," in Proceedings of the 2nd Conference of Engineering Surveying (INGEO '02), pp. 45-52, Bratislava, Slovakia, November 2002.

[4] G. W. Roberts, E. Cosser, X. Meng, and A. Dodson, "High frequency deflection monitoring of bridges by GPS," Journal of Global Positioning Systems, vol. 3, no. 1-2, pp. 226-231, 2004.

[5] X. Meng, G. W. Roberts, A. H. Dodson, E. Cosser, J. Barnes, and C. Rizos, "Impact of GPS satellite and pseudolite geometry on structural deformation monitoring: analytical and empirical studies," Journal of Geodesy, vol. 77, no. 12, pp. 809-822, 2004.

[6] A. P. C. Larocca, R. E. Schaal, M. C. Santos, and R. B. Langley, "Monitoring the deflection of the pierre-laporte suspension bridge with the phase residual method," in Proceedings of the 18th International Technical Meeting of the Satellite Division of the Institute of Navigation (ION GNSS '05), pp. 2023-2028, Long Beach, Calif, USA, September 2005.

[7] W.-S. Chan, Y.-L. Xu, X.-L. Ding, Y.-L. Xiong, and W.-J. Dai, "Assessment of dynamic measurement accuracy of GPS in three directions," Journal of Surveying Engineering, vol. 132, no. 3, pp. 108-117, 2006.

[8] A. Nickitopoulou, K. Protopsalti, and S. Stiros, "Monitoring dynamic and quasi-static deformations of large flexible engineering structures with GPS: accuracy, limitations and promises," Engineering Structures, vol. 28, no. 10, pp. 1471-1482, 2006. 
[9] X. Meng, A. H. Dodson, and G. W. Roberts, "Detecting bridge dynamics with GPS and triaxial accelerometers," Engineering Structures, vol. 29, no. 11, pp. 3178-3184, 2007.

[10] C. Watson, T. Watson, and R. Coleman, "Structural monitoring of cable-stayed bridge: analysis of GPS versus modeled deflections," Journal of Surveying Engineering, vol. 133, no. 1, pp. 23-28, 2007.

[11] T. H. Yi, H. N. Li, and M. Gu, "Full-scale measurements of dynamic response of suspension bridge subjected to environmental loads using GPS technology," Science ChinaTechnological Sciences, vol. 53, no. 2, pp. 469-479, 2010.

[12] F. Moschas and S. Stiros, "Measurement of the dynamic displacements and of the modal frequencies of a short-span pedestrian bridge using GPS and an accelerometer," Engineering Structures, vol. 33, no. 1, pp. 10-17, 2011.

[13] P. Psimoulis, S. Pytharouli, D. Karambalis, and S. Stiros, "Potential of Global Positioning System (GPS) to measure frequencies of oscillations of engineering structures," Journal of Sound and Vibration, vol. 318, no. 3, pp. 606-623, 2008.

[14] P. A. Psimoulis and S. C. Stiros, "A supervised learning computer-based algorithm to derive the amplitude of oscillations of structures using noisy GPS and Robotic Theodolites (RTS) records," Computers \& Structures, vol. 92-93, pp. 337-348, 2012.

[15] S. B. Im, S. Hurlebaus, and Y. J. Kang, "Summary review of GPS technology for structural health monitoring," Journal of Structural Engineering, vol. 139, no. 10, pp. 1653-1664, 2013.

[16] J. Y. Yu, X. L. Meng, X. D. Shao, B. F. Yan, and L. Yang, "Identification of dynamic displacements and modal frequencies of a medium-span suspension bridge using multimode GNSS processing," Engineering Structures, vol. 81, pp. 432-443, 2014.

[17] A. Dodson, X. Meng, and G. Roberts, "Adaptive method for multipath mitigation and its applications for structural deflection monitoring," in Proceedings of the International Symposium on Kinematic Systems in Geodesy, Geomatics and Navigation (KIS '01), pp. 5-8, Banff, Canada, June 2001.

[18] G. W. Roberts, X. Meng, and A. H. Dodson, "Using adaptive filtering to detect multipath and cycle slips in GPS/accelerometer bridge deflection monitoring data," in Proceedings of the 22nd International Congress of the FIG, pp. 19-26, Washington, DC, USA, April 2002.

[19] F. Moschas and S. Stiros, "Dynamic multipath in structural bridge monitoring: an experimental approach," GPS Solutions, vol. 18, no. 2, pp. 209-218, 2014.

[20] G. W. Roberts, C. J. Brown, X. Meng, O. Ogundipe, C. Atkins, and B. Colford, "Deflection and frequency monitoring of the Forth Road Bridge, Scotland, by GPS," Bridge Engineering, vol. 165, no. 2, pp. 105-123, 2012.

[21] B. A. Shenoi, Introduction to Digital Signal Processing and Filter Design, John Wiley \& Sons, 2005.

[22] J. H. Lodge and M. M. Fahmy, "The bilinear transformation of two-dimensional state-space systems," IEEE Transactions on Acoustics, Speech, and Signal Processing, vol. 30, no. 3, pp. 500502, 1982.

[23] T. W. Parks and J. H. McClellan, "Chebyshev approximation for nonrecursive digital filters with linear phase," IEEE Transactions on Circuit Theory, vol. 19, no. 2, pp. 189-194, 1972. 


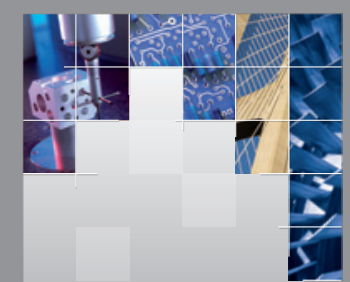

\section{Enfincering}
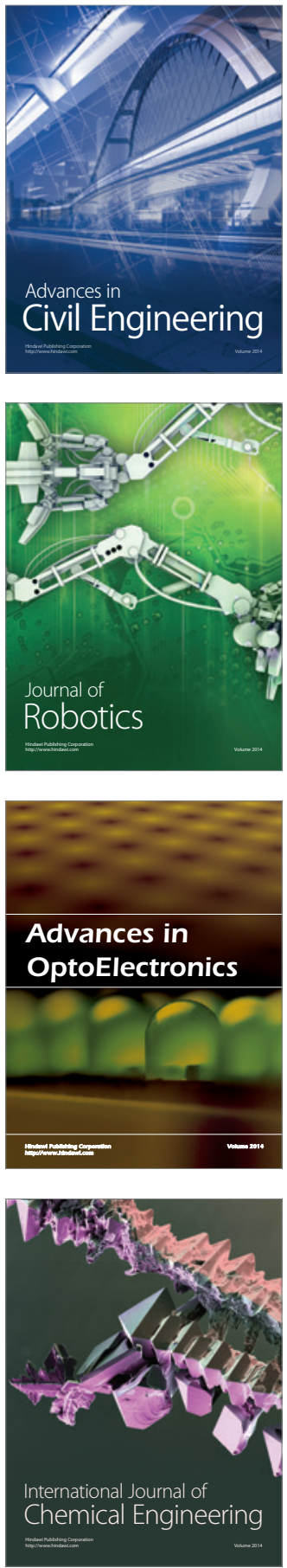

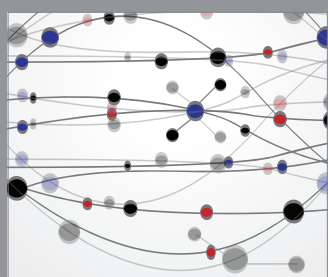

The Scientific World Journal

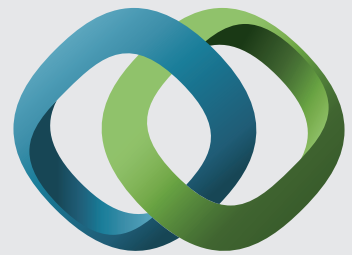

\section{Hindawi}

Submit your manuscripts at

http://www.hindawi.com
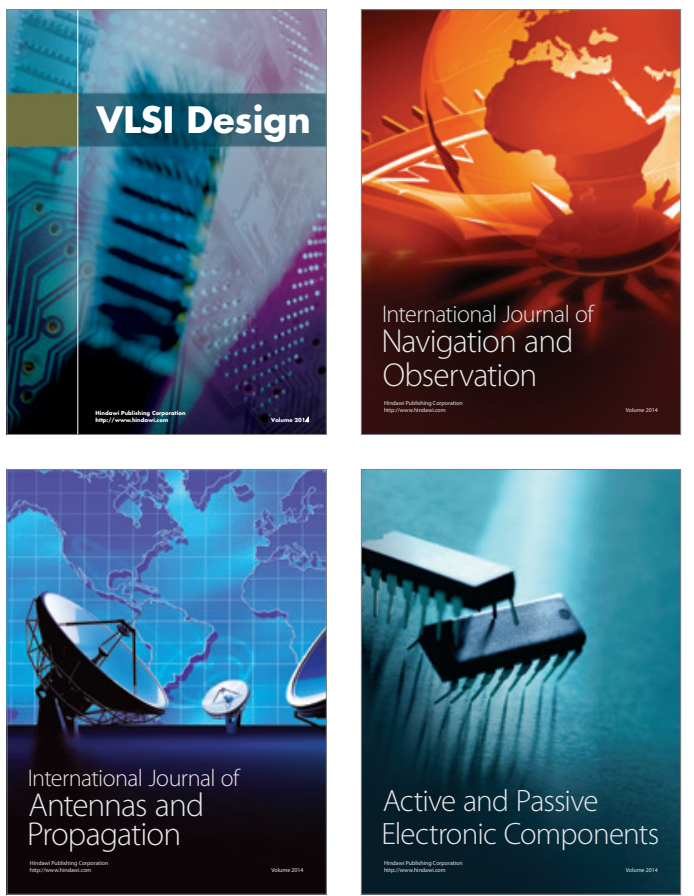
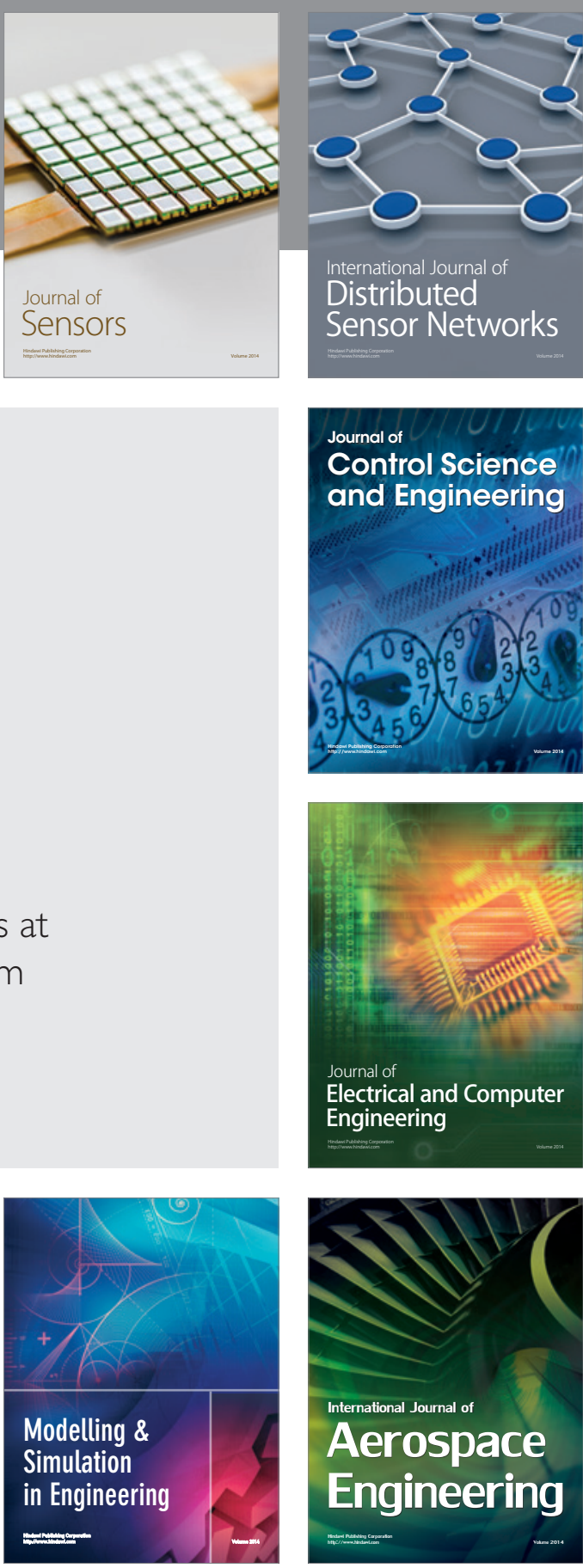

International Journal of

Distributed

Sensor Networks

Journal of

Control Science

and Engineering
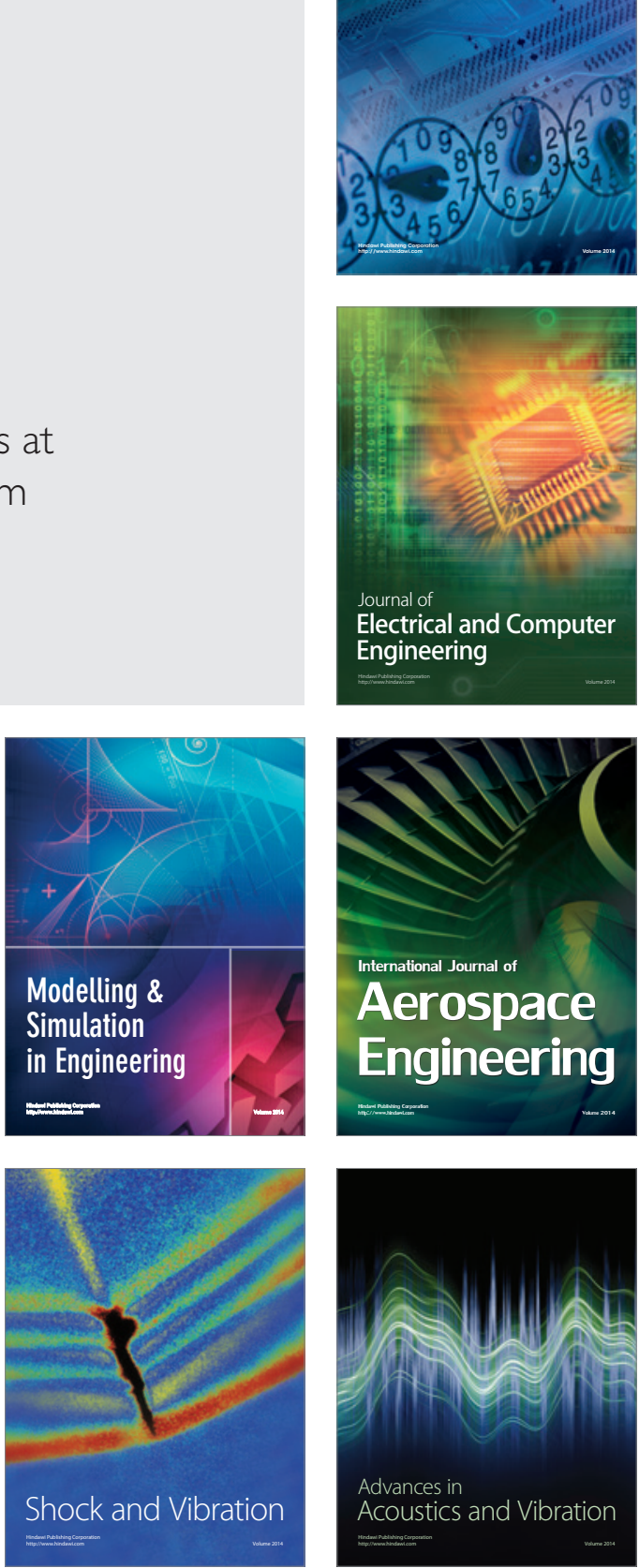